\title{
How effects on health equity are assessed in systematic reviews of interventions (Review)
}

Welch V, Tugwell P, Petticrew M, de Montigny J, Ueffing E, Kristjansson B, McGowan J,

Benkhalti Jandu M, Wells GA, Brand K, Smylie J

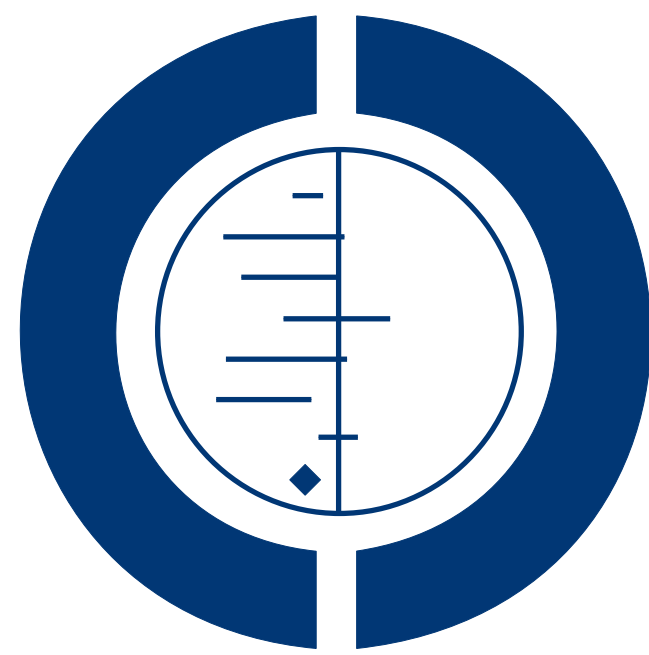

\section{THE COCHRANE COLLABORATION $^{\circledR}$}

This is a reprint of a Cochrane review, prepared and maintained by The Cochrane Collaboration and published in The Cochrane Library 2010, Issue 12

http://www.thecochranelibrary.com

\section{WILEY}

How effects on health equity are assessed in systematic reviews of interventions (Review)

Copyright $\odot 2010$ The Cochrane Collaboration. Published by John Wiley \& Sons, Ltd. 
TABLE OF CONTENTS

HEADER . . . . . . . . . . . . . . . . . . . . . . . . . . . . . . . . . . . . . . . 1

ABSTRACT . . . . . . . . . . . . . . . . . . . . . . . . . . . . . . . . . . . . . . . . 1

PLAIN LANGUAGE SUMMARY . . . . . . . . . . . . . . . . . . . . . . . . . . . . . . . . . . . 2

BACKGROUND . . . . . . . . . . . . . . . . . . . . . . . . . . . . . . . . . . . . . . . . .

OBJECTIVES . . . . . . . . . . . . . . . . . . . . . . . . . . . . . . . . . . . . . . . $4 \begin{gathered}4 \\ \text { O }\end{gathered}$

METHODS . . . . . . . . . . . . . . . . . . . . . . . . . . . . . . . . . . . . . . . . .

RESULTS . . . . . . . . . . . . . . . . . . . . . . . . . . . . . . . . . . . . . . . 8

Figure 1. . . . . . . . . . . . . . . . . . . . . . . . . . . . . . 8

Figure 2. . . . . . . . . . . . . . . . . . . . . . . . . . . . . . . . . . . . . . .

DISCUSSION . . . . . . . . . . . . . . . . . . . . . . . . . . . . . . . . . . . . . 13

AUTHORS' CONCLUSIONS . . . . . . . . . . . . . . . . . . . . . . . . . . . . . . . . . . .

ACKNOWLEDGEMENTS . . . . . . . . . . . . . . . . . . . . . . . . . . . . . . . . . . .

REFERENCES . . . . . . . . . . . . . . . . . . . . . . . . . . . . . . . . . . . . . 16

CHARACTERISTICS OF STUDIES . . . . . . . . . . . . . . . . . . . . . . . . . . . . . . . . . . . 21

DATA AND ANALYSES . . . . . . . . . . . . . . . . . . . . . . . . . . . . . . . . . . . . . . 48

ADDITIONAL TABLES . . . . . . . . . . . . . . . . . . . . . . . . . . . . . . . . . . . 48

APPENDICES . . . . . . . . . . . . . . . . . . . . . . . . . . . . . . . . . . . . . 54

CONTRIBUTIONS OF AUTHORS . . . . . . . . . . . . . . . . . . . . . . . . . . . . . . . . . .

DECLARATIONS OF INTEREST . . . . . . . . . . . . . . . . . . . . . . . . . . . . . . . . . . . . . . $\quad 62$

SOURCES OF SUPPORT . . . . . . . . . . . . . . . . . . . . . . . . . . . . . . . . . . . . . . . . . . . . . .

DIFFERENCES BETWEEN PROTOCOL AND REVIEW . . . . . . . . . . . . . . . . . . . . . . . . . . . 62

INDEX TERMS . . . . . . . . . . . . . . . . . . . . . . . . . . . . . . . . . . . . 62

How effects on health equity are assessed in systematic reviews of interventions (Review)

Copyright $\odot 2010$ The Cochrane Collaboration. Published by John Wiley \& Sons, Ltd. 


\title{
[Methodology Review]
}

\section{How effects on health equity are assessed in systematic reviews of interventions}

\author{
Vivian Welch ${ }^{1}$, Peter Tugwell ${ }^{2}$, Mark Petticrew ${ }^{3}$, Joanne de Montigny ${ }^{4}$, Erin Ueffing ${ }^{1}$, Betsy Kristjansson ${ }^{5}$, Jessie McGowan ${ }^{6}$, Maria \\ Benkhalti Jandu ${ }^{7}$, George A Wells ${ }^{8}$, Kevin Brand ${ }^{4}$, Janet Smylie ${ }^{9}$ \\ ${ }^{1}$ Centre for Global Health, Institute of Population Health, University of Ottawa, Ottawa, Canada. ${ }^{2}$ Centre for Global Health, Institute \\ of Population Health, Department of Medicine, Ottawa Hospital, Ottawa, Canada. ${ }^{3}$ Department of Social \& Environmental Health \\ Research, Faculty of Public Health \& Policy, London School of Hygiene and Tropical Medicine, London, UK. ${ }^{4}$ Ottawa, Canada. \\ ${ }^{5}$ School of Psychology, Faculty of Social Sciences, University of Ottawa, Ottawa, Canada. ${ }^{6}$ Institute of Population Health/Ottawa \\ Health Research Institute, University of Ottawa, Ottawa, Canada. ${ }^{7}$ Center for Global Health, Institute of Population Health, University \\ of Ottawa, Ottawa, Canada. ${ }^{8}$ Cardiovascular Research Reference Centre, University of Ottawa Heart Institute, Ottawa, Canada. \\ ${ }^{9}$ Toronto, Canada \\ Contact address: Vivian Welch, Centre for Global Health, Institute of Population Health, University of Ottawa, 1 Stewart Street, Room \\ 206, Ottawa, Ontario, K1N 6N5, Canada. vivian.welch@uottawa.ca.
}

Editorial group: Cochrane Methodology Review Group.

Publication status and date: New, published in Issue 12, 2010.

Review content assessed as up-to-date: 12 October 2010.

Citation: Welch V, Tugwell P, Petticrew M, de Montigny J, Ueffing E, Kristjansson B, McGowan J, Benkhalti Jandu M, Wells GA, Brand K, Smylie J. How effects on health equity are assessed in systematic reviews of interventions. Cochrane Database of Systematic Reviews 2010, Issue 12. Art. No.: MR000028. DOI: 10.1002/14651858.MR000028.pub2.

Copyright (C) 2010 The Cochrane Collaboration. Published by John Wiley \& Sons, Ltd.

\begin{abstract}
A B S T R A C T
Background

Enhancing health equity has now achieved international political importance with endorsement from the World Health Assembly in 2009. The failure of systematic reviews to consider effects on health equity is cited by decision-makers as a limitation to their ability to inform policy and program decisions.
\end{abstract}

Objectives

To systematically review methods to assess effects on health equity in systematic reviews of effectiveness.

\section{Search methods}

We searched the following databases up to July 2 2010: MEDLINE, PsychINFO, the Cochrane Methodology Register, CINAHL, Education Resources Information Center, Education Abstracts, Criminal Justice Abstracts, Index to Legal Periodicals, PAIS International, Social Services Abstracts, Sociological Abstracts, Digital Dissertations and the Health Technology Assessment Database. We searched SCOPUS to identify articles that cited any of the included studies on October 72010.

\section{Selection criteria}

We included empirical studies of cohorts of systematic reviews that assessed methods for measuring effects on health inequalities.

Data collection and analysis

Data were extracted using a pre-tested form by two independent reviewers. Risk of bias was appraised for included studies according to the potential for bias in selection and detection of systematic reviews.

How effects on health equity are assessed in systematic reviews of interventions (Review)

Copyright $\odot 2010$ The Cochrane Collaboration. Published by John Wiley \& Sons, Ltd. 


\section{Main results}

Thirty-four methodological studies were included. The methods used by these included studies were: 1 ) Targeted approaches ( $\mathrm{n}=22$ ); 2) gap approaches $(n=12)$ and gradient approach $(n=1)$. Gender or sex was assessed in eight out of 34 studies, socioeconomic status in ten studies, race/ethnicity in seven studies, age in seven studies, low and middle income countries in 14 studies, and two studies assessed multiple factors across health inequity may exist.

Only three studies provided a definition of health equity. Four methodological approaches to assessing effects on health equity were identified: 1) descriptive assessment of reporting and analysis in systematic reviews (all 34 studies used a type of descriptive method); 2) descriptive assessment of reporting and analysis in original trials (12/34 studies); 3) analytic approaches (10/34 studies); and 4) applicability assessment (11/34 studies). Both analytic and applicability approaches were not reported transparently nor in sufficient detail to judge their credibility.

\section{Authors' conclusions}

There is a need for improvement in conceptual clarity about the definition of health equity, describing sufficient detail about analytic approaches (including subgroup analyses) and transparent reporting of judgments required for applicability assessments in order to assess and report effects on health equity in systematic reviews.

\section{PLAIN LANGUAGE SUMMARY}

\section{How effects on health equity are assessed in systematic reviews of effectiveness}

Health in all countries of the world is unevenly and, to some extent, unfairly distributed according to socioeconomic position. Health and longevity are highest for the richest, and decrease steadily with decreasing socioeconomic status. Avoidable and unfair inequalities have been termed health inequities. Enhancing health equity has now achieved international political importance with endorsement from the World Health Assembly in 2009. The failure of systematic reviews to consider effects on health equity is cited by decisionmakers as a limitation. Hence, there is a need for guidance on the advantages and disadvantages of how to assess effects on health equity in systematic reviews.

This review identified thirty-four methodological studies in which collections of systematic reviews were examined. We identified four methodological approaches to assess the effects on health equity, a descriptive assessment in the reviews, a descriptive assessment of the trials included in the reviews, analytic approaches, and applicability assessment. However, the most appropriate way to address any of these approaches is unclear. There is a need for methodological guidance on how to assess effects on health equity in systematic reviews. Analysis of particular groups of populations need to be justified and reported in sufficient detail to allow their credibility to be assessed. There is a need for improved transparency of judgments about applicability and relevance to disadvantaged populations.

\section{B A C K G R O U N D}

\section{Description of the problem or issue}

Health differences between groups may be due to inequalities in factors such as socioeconomic characteristics. Health inequalities that are unfair and avoidable are classed as health inequities. Health inequities persist, and are worsening, across almost all health problems, both within and between countries. For example, people living in the poorest countries have a life expectancy that is at least
40 years shorter than for people living in the richest countries. Within a single city (Nairobi, Kenya), the mortality rate of children younger than 5 years is 15 per 1000 in high-income areas and 254 per 1000 in the slums (World Health Report 2008). In an update on global trends on child mortality, inequality in underfive mortality across sex and socioeconomic status is increasing in more countries than it is decreasing (You 2010).

The World Health Organization convened the Commission on Social Determinants of Health (CSDH) in 2006 and released its final report in 2008 to assess the evidence on taking action on reducing health inequity (Marmot 2008). The CSDH defined 
health inequity as "the poor health of poor people" both within countries and between countries as due to an "unequal distribution of power, income, goods, and services, globally and nationally, the consequent unfairness in the immediate, visible circumstances of people's lives-their access to health care and education, their conditions of work and leisure, their homes, communities, towns, or cities-and their chances of leading a flourishing life" (Marmot 2008).

Such health inequalities need to be addressed, not only for moral and ethical reasons, but also for economic reasons (Sachs 2001). There is an increasing evidence-base on the effectiveness of interventions for reducing health inequities, both within and between countries. For example, a recent systematic review, which assessed the effects of tobacco control interventions on the socioeconomic gradient in smoking, identified macro-level policies that may reduce socioeconomic differences in smoking (Thomas 2008).

There is increasing acceptance that systematic reviews of the best available evidence are the foremost source of information on which to base evidence-informed policy and practice (Lavis 2009). Indeed, this view has been endorsed by a World Health Assembly resolution, which was based on the Mexico Ministerial Statement on Health Research (58th World Health Assembly Resolution). A similar recommendation emerged during the Role of Science in the Information Society health conference (European Organization for Nuclear Research 2003) that was held as part of the World Summit of the Information Society in December 2003. The recommendation stressed the need for reliable evidence delivered in a timely manner and in the right format. Systematic reviews are a useful basis for decision making because they reduce the chance of being misled, increase confidence in results, and are an efficient use of time (Lavis 2006).

A recent study of policy maker perceptions found that policy makers increasingly consider systematic reviews as a useful source of knowledge to support decision making (Pope 2006). However, decision makers are interested not only in what works, but also in the costs and resources involved in implementation and ensuring continuity, the potential risks or adverse effects, and the distribution of benefit across sociodemographic factors (Lavis 2005). The lack of evidence on the distribution of effects and impact on health equity has been highlighted by policy makers as a major barrier to the use of systematic reviews as a basis for decision making (Petticrew 2004). Unequal benefits or harms across different socioeconomic or demographic population groups could contribute to worsening health equity (Tugwell 2006). In the context of reducing health inequities, decision-makers from diverse organizations may be interested in evidence of effects of interventions on reducing health inequity such as non-governmental organizations and human rights organizations, as well as government decisionmakers in ministries of health and other departments (e.g. financial and agricultural) (Marmot 2008).

Health inequities are defined by Margaret Whitehead as "differences in health which are not only unnecessary and avoidable but, in addition, are considered unfair and unjust" (Whitehead 1992). Assessing the effects of interventions on health equity is difficult because it requires a subjective judgment about both the avoidability and the fairness of the distribution of effects (Kawachi 1999). Hence, assessments of the distribution of effects of interventions across groups of people who may experience health inequities in both clinical trials and systematic reviews focus on differences in health effects that can be measured (Arblaster 1996; Gepkens 1996).

The Campbell and Cochrane Equity Methods Group has adopted the acronym PROGRESS-Plus to identify dimensions across which health inequities may exist: Place of residence (urban/rural), Race/ethnicity, Occupation, Gender, Religion, Education, Socioeconomic status, and Social capital (Tugwell 2006; Evans 2003). The "Plus" in PROGRESS-Plus refers to any additional factors across which health inequalities may exist such as age, disability, and sexual orientation (Kavanagh 2008). The "Plus" could also include factors such as the experience of sexual or physical abuse as a child, which may shape the experience of health inequity later in life.

Despite the demand for equity assessment by policy makers, these assessments are rare in systematic reviews. Only 1 out of 95 randomly sampled Cochrane Reviews assessed differences in effects across PROGRESS factors (Tsikata 2003). This was due to a lack of information in the included trials (only 10\% reported differences across PROGRESS factors), as well as a lack of assessment by the review authors (Tsikata 2003).

\section{Description of the methods being investigated}

The different methods used to describe and assess effects on health inequalities in systematic reviews were investigated. Because health equity requires a subjective judgment about whether differences in health outcomes are unfair, this review focused on the assessment of health inequalities across PROGRESS-Plus factors. We chose PROGRESS-Plus as an organizing framework to assess dimensions across which health inequities exist since it is endorsed by the Campbell and Cochrane Equity Methods Group and also encompasses the factors suggested by the World Health Organization Commission on Social Determinants of Health (Tugwell 2010). We also assessed whether the authors of the included studies described inequalities in health outcomes as unfair and unjust. There are a number of ways to measure health inequalities. For example, health inequalities can be expressed as the difference between the most and least advantaged groups in relative or absolute terms (Keppel 2005), or they can be expressed using more complicated indices such as the Gini index, concentration index (Koolman 2004), or benefit-incidence estimate (Wagstaff 2005). The choice of method and comparator or reference group influences both the magnitude of the result and its interpretation (Keppel 2005). See Table 1 for selected methods of assessing effects on health inequalities. 


\section{How these methods might work}

Relative or absolute differences for health inequalities measured over time can demonstrate either an increase or decrease in health inequalities for the same data, because relative measures are affected by the underlying rate of the reference group. A detailed example of this can be found in Table C of Keppel 2005. Economic measures of health inequalities, such as the Gini index, concentration index, and the benefit-incidence ratio, may be too complex to interpret and require too many data points to be useful in the context of systematic reviews (Tugwell 2006). This methodology review sought to assess whether these methods have been used to assess health inequalities in empirical studies analyzing systematic reviews, and to explore the advantages and disadvantages of each method.

\section{Why it is important to do this review}

Despite the demand for health equity assessment in systematic reviews by policy makers and practitioners, there remains little empirical evidence on which of the different methods available for assessing health inequalities are have been used in the context of systematic reviews of effectiveness, and their advantages and disadvantages.

\section{O B JECT IVES}

We aimed to describe and assess the effects of using different methods to assess health inequalities in empirical research studies of systematic reviews of the effectiveness of interventions. Thus, we aimed to assess whether the authors of the systematic reviews included in the methodology studies presented results on the effects of the interventions for groups of people who could be classified as suffering from health inequity, across one or more of the sociodemographic factors of PROGRESS-Plus.

\section{METHODS}

\section{Criteria for considering studies for this review}

\section{Types of studies}

We included empirical studies of a cohort (more than one) of systematic reviews of health or non-health interventions that assess effects on health across one or more socioeconomic and demographic factors defined by PROGRESS-Plus. The empirical studies needed to assess whether authors of the included systematic review presented or discussed results on the effects of interventions for groups of people who could be classified as suffering from health inequity, across one or more of the sociodemographic factors of PROGRESS-Plus. Empirical studies using qualitative or quantitative approaches were eligible.

Empirical studies could assess the effects of interventions that aim to decrease the category health inequity experienced by a group of people, such as interventions which aim to improve education opportunities or reduce poverty, if they measured effects on health outcomes of these interventions (Gakidou 2010). An example of an eligible study is an empirical study which assessed the the effects of community-based tobacco control interventions for groups of people who could be defined as experiencing health inequity across sex, race/ethnicity or socioeconomic status in six Cochrane reviews (Ogilvie 2004).

We excluded individual systematic reviews assessing health inequalities as we aimed to assess methods for comparing health inequalities across different systematic reviews, rather than within an individual systematic review. Furthermore, including individual systematic reviews might introduce bias because they are less likely to report health inequalities analyses when no substantive differences are found (Chan 2004).

Overviews of systematic reviews synthesize evidence from multiple systematic reviews of interventions into one document (Cochrane Handbook 2009). Overviews of systematic reviews were eligible if they assessed effects of interventions for groups of people who could be classified as suffering from health inequity.

\section{Types of data}

We assessed data from published or unpublished empirical studies of a cohort of systematic reviews on the advantages, disadvantages and feasibility of methods used to assess effects of interventions in groups of people who could be defined as experiencing health inequity. We extracted data on the advantages and disadvantages (or strengths and limitations) of each of the methods as described by the authors of the empirical studies. We used PROGRESSPlus to categorize groups of people who might experience health inequity. The place of residence of high-income country compared to low and middle income country was also considered as a factor across which health inequity may exist. We used the classification of the World Bank for high, middle and low income countries. Since the political climate of a country interacts with the income level of the country in relation to the existence of health inequities, we considered differences in political stability and climate in the "Plus" factor of PROGRESS-Plus. For example, although Saudi Arabia is a high-income country, the experience of health inequity by religious groups and women is different than in a Western industrialized country.

For the health inequalities to be judged inequitable, unfairness and avoidability (or remediability) need to be assessed. Therefore, we assessed whether the empirical studies of cohorts of systematic 
reviews included a judgment about the fairness and avoidability of health differences. If the studies made no judgment about health equity, we used the Whitehead criteria of avoidability and unfairness to make a judgment about whether health differences across these factors for the particular intervention and setting could be considered health inequities (Whitehead 1992). Judgments made using these criteria were documented, including whether sufficient information was available to make such a decision. For example, sex differences that are due to unavoidable underlying differences in biology would not meet the criteria for a health inequity, such as differences in rates of breast cancer across sex, or manifestations of haemophilia in males (Whitehead 1992). We expected substantial heterogeneity in definitions of equity. Therefore, we documented the variety of existing definitions to help inform the development of universally accepted definitions.

Empirical studies of cohorts of systematic reviews were included if they focused on the following:

1. Targeted approaches: evaluating effects (benefits or harms) in disadvantaged populations only (i.e. populations who suffer from health inequity due to their characteristics across one or more of PROGRESS-Plus factors).

2. Gap approaches: evaluating differences in effects (benefits or harms) between the most and least advantaged groups (see Table 1).

3. Gradient approaches: evaluating effects (benefits or harms) on the gradient from the most disadvantaged to the least disadvantaged groups (Table 1).

\section{Types of methods}

We compared different methods used by the empirical studies for assessing effects on health inequalities in terms of: the expertise required to implement the strategy at the level of the overview/ empirical study; the availability of data from the systematic reviews as assessed by the authors of the empirical study; their advantages and disadvantages; and whether and how judgments about health equity are made (e.g. judgments about fairness and avoidability of differences in benefits or harms).

\section{Types of outcome measures}

\section{Primary outcomes}

- Advantages and disadvantages of the methods used for assessing health inequalities, based on descriptions of the authors of the empirical studies and a judgment by the data extractors assessed from the perspective of a user of the empirical study. This judgment was made by asking the data extractors to consider a decision-maker's perspective. These judgments were compared and agreed to. We also discussed these judgments with other authors who were not responsible for the data extraction.
- Whether the analyses of effects on health inequalities across PROGRESS-Plus factors met the following criteria for credible subgroup analyses, as recommended by the Cochrane Handbook (Oxman 1992, Cochrane Handbook 2009).

i) Clinically important difference.

ii) Statistically significant difference.

iii) A priori hypothesis.

iv) Subgroup analysis is one of a small number of hypotheses tested.

v) Difference suggested by comparisons within primary studies of meta-analyses.

vi) Difference consistent across primary studies of metaanalyses.

vii) Indirect evidence that supports hypothesized difference.

Four additional criteria have been proposed since this protocol was written for assessing the credibility of subgroup analyses: 1) consideration of baseline characteristics; 2) independence of the subgroup effect (i.e. the subgroup effect is not confounded by association with another factor); 3) a priori specification of the direction of effect; and 4) consistency across related outcomes (Sun 2010). These four criteria have not been assessed. They will be included in the first update of this review.

\section{Secondary outcomes}

- Whether and how health inequity was defined and measured (e.g. whether proxy measures, such as nutritional status, are used).

- Information on the availability of data from primary trials or meta-analyses to conduct analyses across PROGRESS-Plus factors.

- What factors are associated with health inequalities (e.g. the types of primary studies included in the systematic reviews and implementation factors, such as the degree to which flexibility was allowed in the implementation).

- Implications for practice, policy, and research based on analysis of effects on health inequalities.

\section{Search methods for identification of studies}

The search strategy was developed by one author (VW) using a systematic scoping exercise to assess the effects of different $\mathrm{MeSH}$ terms and the use of limits on publication type (i.e. limited to meta-analyses or systematic reviews) and type of studies (i.e. intervention studies). The terms developed for equity were based on the elements of PROGRESS-Plus, and testing that our group has done on the use of filters for health equity (McGowan 2003). We tested the inclusion of a term related to geographic disparities (including terms such as resource-poor settings and low and middle income countries) because the search was very broad without 
using restrictions. We tested this strategy to ensure that known relevant studies were retrieved, including one study of the assessment of low and middle income country concerns in systematic reviews (Nasser 2007). The final search strategy does not include limitations on publication type as these were found to be too restrictive. An information scientist (JM) reviewed the search strategy, as recommended by the Peer Review of Electronic Search Strategies (PRESS) guidelines (Sampson 2008).

The search strategy was not limited by publication type or study design as there is no indexing term for studies that assess cohorts of systematic reviews. We included published and unpublished articles, as well as abstracts.

\section{Electronic searches}

We searched:

- the Cochrane Methodology Register (to July 2, 2010);

- MEDLINE (January 1950 to July 2, 2010) using the Ovid interface;

- EMBASE (1980 to July 2, 2010) using the OVID interface;

- PsycINFO (1806 to July 2,2010$)$ using the OVID interface

- CINAHL (1998 to July 2, 2010).

See Appendix 1 for the MEDLINE search strategy. This search strategy was adapted for the other electronic databases (Appendix 2).

To identify systematic reviews of social, legal, and educational interventions, we searched non-health literature databases using the Scholars Portal interface including the Education Resources Information Center (ERIC, 1965 to July 2, 2010), Education Abstracts (1983 to July 2, 2010), Criminal Justice Abstracts (1968 to July 2, 2010), Index to Legal Periodicals (1994 to July 2, 2010), PAIS International (public affairs, public and social policies, international relations - 1972 to July 2, 2010), Social Services Abstracts (1979 to July 2, 2010), Sociological Abstracts (1952 to July 2, 2010), and Digital Dissertations (1997 to July 2, 2010). We also searched the reports of national health technology assessment organizations using the Health Technology Assessment Database (available on the Cochrane Library) to July 2, 2010.

\section{Searching other resources}

We also handsearched abstracts from recent Cochrane and Campbell Collaboration Colloquia (2007 to 2010).

We used SCOPUS to identify citations of potentially included studies. SCOPUS is a citation tracking database of over 18,000 titles across scientific, technical, medical and social sciences fields as well as arts and humanities. We conducted a search of SCOPUS for all included studies on October 7 2010. This identified any articles which had cited one of the included studies.

We searched the reference lists of included studies for other potentially relevant studies, and we contacted the authors of included studies to ask if they knew of similar studies.
We also asked the editorial board members of the Cochrane and Campbell Equity Methods Group whether they were aware of other potentially relevant studies.

Unpublished studies and abstracts were identified through the methods above of contacting experts, authors and searching conference proceedings of the Cochrane and Campbell Colloquia.

\section{Data collection and analysis}

\section{Selection of studies}

Two review authors (chosen from EU, JdM, MB, BD and VW) independently screened the titles and abstracts of all references retrieved by the search strategy to exclude those that were obviously irrelevant. They were not blinded to the authorship of the titles and abstracts because this is difficult to achieve and may not affect the screening process (Berlin 1997).

Potentially relevant articles were retrieved and screened independently by two review authors (chosen from EU, JdM, BD, MB, and VW) using an eligibility checklist. Disagreements were resolved by consensus in consultation with another author (MP or PT). We documented all reasons for exclusion at both stages of screening for entry into a PRISMA (Preferred Reporting Items for Systematic reviews and Meta-Analyses) flowchart (Moher 2009).

\section{Data extraction and management}

Two review authors (chosen from EU, JdM, MB, and VW) extracted data independently from the included empirical studies using a pre-tested data extraction form designed in an Excel spreadsheet (see Appendix 3), which was used to manage and summarize data. For consistency, VW extracted data from each study. The assignment of articles to the other data extractors was based on their time available to contribute. We compared the data extracted by both review authors for each study. Disagreements were resolved by consensus. Another author (MP or PT) mediated when consensus could not be reached.

We extracted data on:

1. how the sample of systematic reviews was selected;

2. the characteristics of the systematic reviews (population, intervention, comparison, outcomes, study designs included, quality assessment, year of publication);

3. characteristics of the interventions being studied (e.g. pharmacologic, implementation, health services);

4. the method used to assess effects on health equity (how and whether equity is defined; which elements of PROGRESS-Plus were compared; whether other factors, such as the study design of primary studies, setting, or context, were assessed that might explain differences in effects across PROGRESS-Plus factors);

5. how effects were compared (e.g. relative or absolute differences, or gradient approaches such as the Gini coefficient); 
6. the size of the difference in effects across different populations defined by PROGRESS-Plus.

We also assessed whether data on PROGRESS-Plus was available from the systematic reviews, as reported by the authors of the empirical studies.. We did not verify this data availability by consulting the systematic reviews.

\section{Assessment of risk of bias in included studies}

Two of the four possible reasons for systematic error or bias were addressed: selection bias and detection bias (Higgins 2008). For each of these possible sources of bias, we assessed the transparency of the methods described by the authors and the potential for bias in the methods used to select and analyze the systematic reviews included in the cohort. We did not assess performance bias as this is related to exposure to the intervention in randomized controlled trials and does not apply to empirical studies of cohorts of systematic reviews. In the context of empirical studies designed to assess health inequalities in cohorts of systematic reviews, selection and detection bias were defined as follows.

- Selection bias: potential for bias in the selection of the systematic reviews to be included or excluded. We extracted details on the inclusion and exclusion criteria used to select systematic reviews.

- Detection bias: potential for bias in the assessment of analytic methods and outcomes in cohorts of systematic reviews. We extracted information on how the details of the analysis of effects on health equity were extracted from the systematic reviews.

We did not assess attrition bias because in the context of this review, attrition bias (defined as systematic differences between groups in withdrawals) refers to the same concept as selection bias.

\section{Measures of the effect of the methods}

We conducted a comparative analysis of the methods used to assess effects on health inequalities by comparing the advantages and disadvantages of each of the methods, as judged by the data extractors, based on the description by the authors of the empirical studies and considering the perspective of the reader or user of the empirical study.

We extracted details reported by the authors of the empirical studies on the availability of data from the systematic reviews and their included primary studies, as well as on the methods used to compare differences in disadvantaged populations to the overall pooled effect.

We also compared any subgroup analyses against the seven criteria for credible subgroup analyses and four additional criteria (Oxman 1992, Sun 2010). Additional criteria for subgroup analyses for clinical trials and meta-analyses were also considered for this comparison (Rothwell 2005; Thompson 2005).

\section{Dealing with missing data}

We planned to contact authors of the included studies if insufficient information was available regarding sample generation, methods, and outcomes. We only contacted one author for additional information, to request the criteria used to assess applicability and equity (Althabe 2008). These authors provided their checklists.

\section{Assessment of heterogeneity}

Results were not pooled. Results for each outcome (e.g. data availability, advantages, disadvantages, and credibility of subgroup analyses) were presented across each factor of PROGRESS-Plus for each included study.

\section{Assessment of reporting biases}

Reporting bias occurs when dissemination of research findings is influenced by the nature and direction of results (Higgins 2008). Positive studies, in the context of this review, include studies that are able to show statistically significant and substantive differences in effects across one or more PROGRESS-Plus categories. We attempted to minimize the identification of only studies with positive results by using a comprehensive search strategy in diverse electronic databases, assessing relevant conference proceedings, reviewing citations, and contacting both the authors of eligible empirical studies and other experts.

\section{Data synthesis}

Results were synthesized in tables. Where data were available on subgroup analyses, we summarized the methods used to compare effects in different populations across PROGRESS-Plus categories. For subgroup analyses, we assessed the first criteria of clinical importance of the difference in effects by assessing whether the authors of the empirical study described the clinical importance. If the authors did not judge the clinical importance, we compared the pooled effect size to the effect size reported in the different subgroups, either using mean differences or risk ratios and their 95\% confidence intervals (CIs).

\section{Subgroup analysis and investigation of heterogeneity}

As this is a descriptive methodology review, the results were not pooled and subgroup analyses was not conducted.

\section{Sensitivity analysis}

As this is a descriptive methodology review, the results were not pooled and sensitivity analyses were not conducted. 


\section{R E S U L T S}

\section{Description of studies}

See: Characteristics of included studies; Characteristics of excluded studies; Characteristics of ongoing studies.

\section{Results of the search}

10,058 potential articles were screened for inclusion (Figure 1). Of these, 102 potentially eligible studies were retrieved in full text.

Figure I. Figure 2: PRISMA Chart

\section{PRISMA chart}

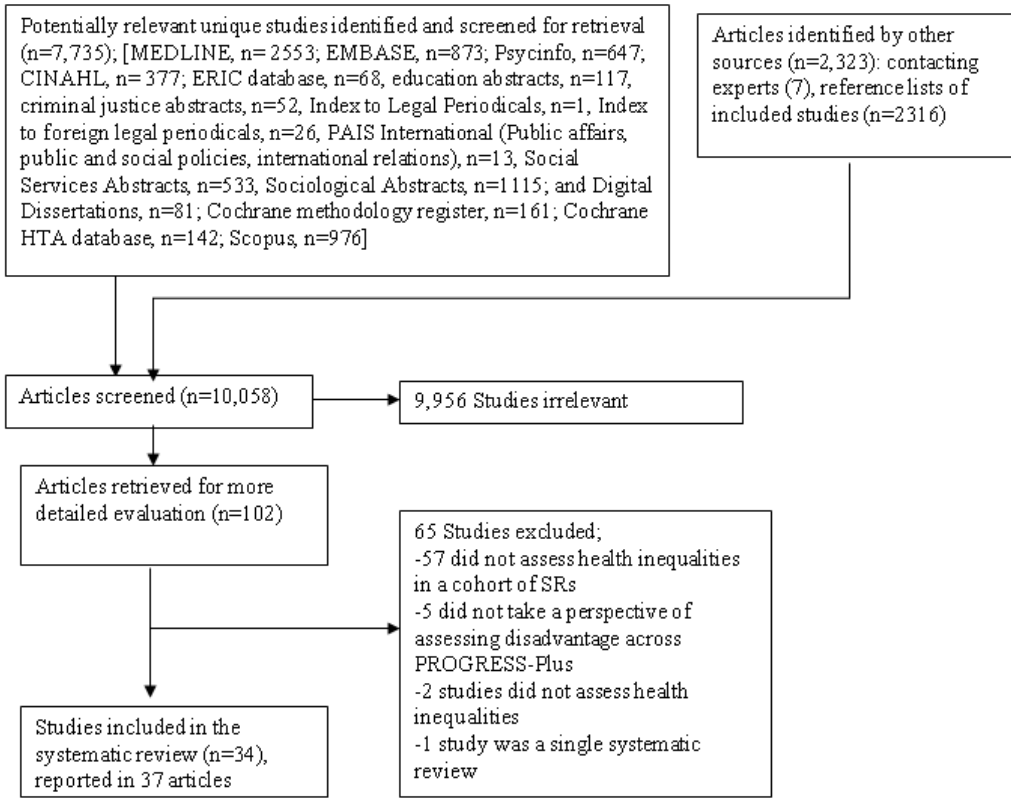

Note: PROGRESS-Plus: Place of residence (urban/rural), Race/ethnicity, Occupation, Gender, Religion, Education, Socioeconomic status and Social Capital; "Plus" covers other factors associated with unequal opportunities to be healthy such as disability and age; SR: systematic review; ERIC- Education Resources Information Center

\section{Included studies}

Thirty-four empirical studies (described in 37 articles) of cohorts of systematic reviews were included which assessed effects on health inequalities across one or more PROGRESS-Plus factor.
These included studies were identified by electronic databases $(\mathrm{n}=$ 25), searching SCOPUS for references to included studies $(\mathrm{n}=5)$ (Barros 2010; Doull 2010; Bhutta 2008; Chopra 2008; Ball 2002), handsearching reference lists $(\mathrm{n}=2)$ (Shea 2009, Jones 2003) and

How effects on health equity are assessed in systematic reviews of interventions (Review) 
contact with experts $(n=2)(B a m b r a ~ 2010$; Odierna 2009). One ongoing doctoral thesis study assessing equity aspects in health technology assessment reports was identified (Panteli 2009). Four studies were identified as abstracts (Odierna 2009, Nasser 2007, Tsikata 2003, Doull 2010). Two studies remained unpublished except as abstracts, as of publication of this review (Nasser 2007, Tsikata 2003).

The methods used by these included studies were: 1) Targeted approaches $(n=22) ; 2)$ gap approaches $(n=12)$ and gradient approach $(n=1)$. One study was classified as both a gap approach and a targeted approach (Sherr 2009), since it assessed differences in effects across sex (gap approach), as well as effects of interventions aimed only at women (targeted approach). Gender or sex was assessed in eight out of 34 studies, socioeconomic status in 10 studies, race/ethnicity in seven studies, age in seven studies, LMIC in 14 studies, and two studies assessed all PROGRESS-Plus factors. The rationale for assessing effects on health inequalities in these studies was to better understand the mechanism of action of the intervention in five studies, to improve understanding of what works to reduce health inequalities in ten studies, to assess direct evidence on effectiveness in particular populations in nine studies, and to assess applicability or relevance of evidence for disadvantaged populations or settings in ten studies. The number of meta-analyses or systematic reviews included in these studies ranged from 5 to 420 systematic reviews. Six out of 34 of these studies assessed cohorts of exclusively Cochrane reviews.

We included nine overviews of effectiveness of interventions to improve maternal, neonatal and child health with a focus on LMIC. These overviews are the studies from the Global report on preventing preterm birth and stillbirth (Barros 2010), the Lancet child survival series (Jones 2003), the Lancet series on Alma-Ata rebirth and revision (Bhutta 2008), the Lancet neonatal survival series (Darmstadt 2005), the Lancet maternal and child undernutrition series (Bhutta 2008), and the Biomed Central series on reducing stillbirths (Bhutta 2009, Haws 2009, Menezes 2009, Yakoob 2009). These overviews of effectiveness were based on a combination of systematic reviews, randomized trials and observational studies, with particular emphasis on effectiveness and relevance in LMIC. The systematic reviews cited for these series drew heavily on Cochrane reviews since they were considered high quality and reliable systematic reviews by the authors of these series (for example, 81/102 systematic reviews cited in the 2009 Biomed Central reducing stillbirths series were Cochrane reviews).

\section{Excluded studies}

65 studies that were retrieved in full text were excluded. 57 studies were excluded since they clearly did not meet the inclusion criteria because they were not cohorts of systematic reviews $(n=38)$ or because they did not assess health inequalities across one or more PROGRESS-Plus factor $(\mathrm{n}=19)$. Eight studies which appeared to meet both of these inclusion criteria, but on closer examination failed, are described in the Table of Excluded Studies.

Five studies were excluded since they did not describe a focus on health equity (Gulmezoglu 1997; Barlow 2004; Espinosa-Aguilar 2007; Craig 2003; Gaes 1999) (See Table of Excluded Studies). These studies assessed health effects of interventions in specific populations that could be classified as vulnerable across one or more PROGRESS-Plus factor (e.g. sexual offenders, elderly, children with chronic disease), but the authors of the study did not describe a focus on vulnerability or disadvantage. Two studies of cohorts of systematic reviews were excluded since they did not assess health inequalities (Ahmad 2010, AHRQ 2010). One study that assessed health inequalities was excluded since it was a single systematic review of multiple interventions, not a cohort of systematic reviews (Thomas 2008).

\section{Risk of bias in included studies}

From the reporting of each cohort, we assessed the risk of selection bias to be low for 27 out of 34 included studies (Figure 2). These 27 empirical studies of a cohort of systematic reviews reported using an explicit search method, and screening titles for inclusion using prespecified criteria to identify relevant systematic reviews. Detection bias was low for 11 out of 34 of the included studies which reported explicit methods of data extraction, using forms and data verification. The other 23 studies did not fully report methods for data extraction and verification, and may be subject to a higher risk of bias due to missing relevant information.

How effects on health equity are assessed in systematic reviews of interventions (Review) 
Figure 2. Risk of bias summary: review authors' judgements about each risk of bias item for each included study.

\begin{tabular}{|c|c|c|}
\hline & 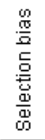 & 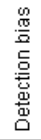 \\
\hline Adamek 2008 & + & $?$ \\
\hline Althabe 2008 & + & + \\
\hline Ball 2002 & $?$ & $\Theta$ \\
\hline Bambra 2010 & + & + \\
\hline Barros 2010 & + & $?$ \\
\hline Bartels 2003 & + & - \\
\hline Bhutta 2008 & $?$ & + \\
\hline Bhutta 2008a & $?$ & $?$ \\
\hline Bhutta 2009 & + & $?$ \\
\hline Browne 2004 & + & + \\
\hline Chopra 2008 & + & + \\
\hline D'Souza 2004 & + & $?$ \\
\hline Darmstadt 2005 & $?$ & $?$ \\
\hline Darmstadt 2009 & + & $?$ \\
\hline Doull 2010 & + & + \\
\hline Haws 2009 & + & $?$ \\
\hline Jepson 2010 & + & $?$ \\
\hline Johnson 2003 & + & $?$ \\
\hline Jones 2003 & $?$ & $?$ \\
\hline Lewin 2008 & + & + \\
\hline Main 2008 & + & + \\
\hline Menezes 2009 & + & $?$ \\
\hline Morrison 2004 & + & $?$ \\
\hline Nasser 2007 & + & O \\
\hline Odierna 2009 & + & + \\
\hline Ogilvie 2004 & + & $?$ \\
\hline Shea 2009 & + & $?$ \\
\hline Sherr 2009 & $?$ & $?$ \\
\hline Stewart 2006 & + & + \\
\hline Tsikata 2003 & + & + \\
\hline Tugwell 2008 & + & + \\
\hline Vergidis 2009 & - & م \\
\hline Viswanathan 2008 & + & $?$ \\
\hline Yakoob 2009 & + & $?$ \\
\hline
\end{tabular}


Across studies, there is a low risk of selection bias since all of these empirical studies of cohorts of systematic reviews used a systematic search to identify studies that met predetermined criteria. Six out of 34 of these studies assessed solely cohorts of Cochrane systematic reviews which may be least likely to assess effects on health inequalities since they are most likely to assess efficacy questions where differences in effectiveness across PROGRESS-Plus factors are least likely to occur (Tugwell 2008).

\section{Effect of methods}

\section{Definition of health equity}

Equity was defined in three studies, as unfair and avoidable inequalities in health across socioeconomic strata (Tugwell 2008; Tsikata 2003; Odierna 2009). None of the studies described making a judgment about the fairness of differences in health. Twelve studies describe higher burden of disease in disadvantaged populations as avoidable or preventable, without making a statement about fairness or justice. One study described using an "equity lens" (Main 2008) to assess whether systematic reviews could be used to answer questions about reducing health inequalities across SES, ethnicity or education. Three studies used the "SUPPORT equity checklist" (Lewin 2008; Althabe 2008; Chopra 2008) which assesses access to health care across LMIC, gender, age, ethnicity or SES (Appendix 4). Three studies focused on assessing differences across gender or sex by conducting a gender analysis (Johnson 2003, Sherr 2009) or gender and sex based analysis (Doull 2010). In one study, the rationale for conducting a gender analysis was due to differences in biological susceptibility HIV/AIDS as well as the social susceptibility through gender roles and discrimination (Sherr 2009). Nine studies focused on assessing relevance of systematic reviews for decisions about health care in low and middle income countries (LMIC)(Nasser 2007; Tugwell 2008; Tsikata 2003; Chopra 2008; Menezes 2009; Bhutta 2009; Haws 2009; Darmstadt 2009; Yakoob 2009). Two of these studies described differences in access to health care across geography and socioeconomic status in LMIC as inequitable (Lewin 2008; Chopra 2008).

\section{Methods identified to assess consideration of effects on health inequalities or health inequities}

We identified four categories of methods used to assess whether systematic reviews considered effects of interventions on health equity: 1) descriptive assessment of systematic reviews; 2) descriptive assessment of primary studies included in the systematic reviews; 3) analytic approaches and 4) judgment of applicability to disadvantaged populations or settings. See Table 2.

\section{1) Descriptive assessment of systematic reviews}

All 34 studies used at least one of the five descriptive approaches described below to assess whether their sample of SRs had considered effects of interventions on health equity.

1a) Mention of PROGRESS-Plus in introduction, objectives, discussion, implications

Only three methodological studies included in their objectives the assessment of explicit mention of PROGRESS-Plus in the introduction, objectives or discussion. This strategy provides information about whether SRs consider health equity in a broad sense, but provides no evidence on effects on health equity.

1b) Methods study assessed whether SRs describe populations in the primary studies across PROGRESS-Plus factors

For the twelve empirical studies which used this method, details on the populations included in the trials were available for $0 \%$ to $57 \%$ of SRs across PROGRESS-Plus factors. Sex distribution of the population was the most well-reported PROGRESS-Plus factor (90/153 SRs). The advantage of this approach is that information about the diversity of populations increases confidence in applying results across different populations and settings. The disadvantages are lack of data, and that description of populations does not assess differences in effects across these populations.

1c) Methods study assesses whether SR describes primary research as targeted at disadvantaged populations across PROGRESS-Plus

Twenty-two methodology studies assessed whether systematic reviews described interventions as being evaluated in specific disadvantaged populations. Of these, seven methodology studies selected SRs which focused only on disadvantaged populations (targeted). The disadvantaged populations targeted in these seven methodology studies were elderly with mental health problems (Adamek 2008; Bartels 2003), youth with disabilities (Stewart 2006), socially disadvantaged mothers (D’Souza 2004), people in low and middle income countries (Nasser 2007), women at risk for low birth weight children (Ball 2002), and minority populations, injection drug users and people with HIV (Vergidis 2009). These methodology studies described these populations as disadvantaged because of avoidable and unfair poorer health outcomes than other people due to lack of evidence, lack of guidelines or lack of resources to access and use preventive and curative interventions.

Ten methodology studies reported assessing whether the SRs described at least one study conducted in a disadvantaged population. While this descriptive method identifies whether interventions have been evaluated in disadvantaged populations, it does not assess the effects on health inequalities. Furthermore, it can be misleading since SRs with no studies in disadvantaged populations may still be relevant and applicable to disadvantaged populations. 1d) Methodology study assessed whether SRs have outcomes

How effects on health equity are assessed in systematic reviews of interventions (Review) 
related to equity of access

Seven methodology studies described whether SRs reported outcomes related to access to care or coverage of health services. Access to health care across disadvantaged groups (e.g. rural, low SES, LMIC, ethnicity) was reported in 18/173 SRs in these methodology studies. Access to health care is a determinant of both health and health inequalities. This strategy does not measure effects on health equity. Evidence on access to care may be affected by the eligibility criteria of the methodology studies. For example, one methodology study required that SRs contain information about access to care in LMICs by the focus of the review (Lewin 2008). 1e) Methodology study assesses whether SRs planned or conducted subgroup analyses across one or more PROGRESSPlus factors

Ten methodology studies assessed whether subgroup analysis was conducted in groups of SRs. Outcomes were analyzed using subgroup analysis across one or more PROGRESS-Plus factor in only 22 out of 262 SRs assessed in these methodology studies (8\%). For those that reported details of these subgroup analyses, subgroup differences were assessed across gender/sex $(n=15)$, race/ethnicity $(n=12)$ and socioeconomic status $(n=1)$. Differences in effects across other factors of PROGRESS-Plus were not reported at the level of the SR in these methodology studies (LMIC, place of residence, occupation, religion, social capital). The advantage of this strategy is that subgroup analysis summarizes the data available in specific populations. However, these subgroup analyses are limited in their ability to detect differences due to statistical issues (e.g. post-hoc analyses, probability of finding a false association, lack of data in the primary studies, or lack of reporting stratified data in primary studies) (Bambra 2010). Furthermore, subgroup analyses that were conducted were poorly reported (Table 3 ).

\section{2) Descriptive assessment of primary studies included in the systematic reviews}

2a) Methodology study assesses whether populations in primary studies are described according to PROGRESS-Plus:

Eleven methodology studies retrieved and evaluated primary studies of included SRs to assess whether data was available from primary studies to conduct subgroup analyses in SRs. Population characteristics were reported in primary studies for sex most frequently (209/250 trials), followed by race, education, place of residence, socioeconomic status, occupation and social capital. This strategy has the advantage of assessing whether data is available in primary studies, thus assessing whether there is a risk of bias that PROGRESS-Plus characteristics are under-reported in systematic reviews (Bambra 2010; Tugwell 2008). However, this strategy does not assess effects on health inequalities, and data may not be available from the primary studies stratified by PROGRESS-Plus characteristics.

2b) Methodology study assesses whether subgroup analyses conducted in primary studies:
Six of the methodology studies of systematic reviews assessed whether data was available from the primary studies on population characteristics across PROGRESS-Plus and whether outcomes were analyzed using subgroup analysis in the primary studies (Tsikata 2003). In the included primary studies, outcomes were reported separately for sex most commonly (from 13-36\% of clinical trials), followed by SES (4 out of 103 trials in one study). Advantages of this approach are that more details are available regarding the methods of subgroup analyses by assessing information in the primary studies than in systematic reviews. Disadvantages of this approach are that it is time-consuming to locate and assess all primary studies (Bambra 2010; Ogilvie 2004b).

\section{3) Analytic approaches}

3a) Methodology study to assess association of PROGRESSPlus factors with size of effect

Regression analysis was used by one methodology study of SRs on interventions to improve adherence (Morrison 2004). Data was available for age (8 out of 12 SRs), sex (7 out of 12 SRs) and socioeconomic status (5 out of 12 SRs). One study categorized the effect of gender on outcomes as positive effect, negative effect or no effect (Sherr 2009).

Advantages of assessing association of PROGRESS-Plus factors with size of effect are that it could be used to assess which PROGRESS-Plus factors are associated with effects on health equity and the dose-response of their effect. The disadvantage of this approach is that data may be unavailable (e.g. in Morrison 2004 , one third of SRs lacked data to conduct this analysis).

3b) Methodology study compares effect size using an odds ratio, relative risk or risk difference between two groups across PROGRESS-Plus (e.g. men vs. women)

None of the 34 methodology studies reported a quantitative comparison of the difference between advantaged and disadvantaged populations or settings.

3c) Methodology studies assessed effects of interventions targeted at a specific population which is disadvantaged (e.g. older people with depression, youth with disabilities).

Seven methodology studies searched for systematic reviews of the effects of interventions targeted at populations which were described by the authors as disadvantaged by unequal opportunities for optimal health or high quality health care. One study (Vergidis 2009) assessed effects of interventions to reduce highrisk behaviours in specific populations that are widely acknowledged as disadvantaged (i.e. minority populations, injection drug users, men who have sex with men and people with HIV), but did not make any judgment or statement about vulnerability of these populations. These methodological studies identified a median of 11 SRs (range 5-23), and four studies reported clinically important and statistically significant effect sizes in these populations. The advantage of this approach is that evidence on effectiveness can be directly used to inform decisions about interventions aimed 
at specific disadvantaged populations (e.g. older people with depression) (Adamek 2008) and to identify gaps in the evidencebase. However, this approach may not be possible for some disadvantaged groups where systematic reviews or primary trials have not been conducted. Furthermore, this approach is limited by the methodological quality of the SRs and whether sufficient details about the process of implementation are reported to replicate the interventions. Also, the gap or gradient between these disadvantaged populations and others is not assessed, so the extent to which interventions generate health inequalities is not assessable (Adams 2005).

4) Judgment of applicability to disadvantaged populations or settings

4a) Methodology studies assess applicability to different populations across PROGRESS-Plus

Eleven methodology studies assessed the applicability and relevance of systematic reviews to improve health of people in LMIC (Althabe 2008; Lewin 2008; Chopra 2008). Three methodology studies all used the SUPPORT Collaboration checklists for equity, applicability and scaling up to make judgments about whether the results from systematic reviews could be transferred to LMIC settings and could be expected to confer health benefits (details of SUPPORT checklists available in Appendix 4, and at: http:// www.support-collaboration.org/summaries/methods.htm).

Five studies used the SIGN tools to assess quality and strength of the evidence, including the directness of evidence to LMIC settings (see Appendix 5 and Appendix 6 for details about how applicability and generalizability are assessed using considered judgment).

Three studies used the GRADE tools to assess quality of evidence for each outcome. The GRADE assessment also includes an assessment of directness of evidence to the population of interest, which was people in LMIC in these studies (Lewin 2008, Bhutta 2008, Barros 2010). These three studies do not report how this judgment was made, or when the difference between people in the trials included in the systematic reviews would be large enough to downgrade the quality of evidence for indirectness.

Two studies used criteria of biological plausibility and feasibility of implementation in LMIC to select interventions. These criteria were judged by a panel of experts using Delphi consensus methods (Jones 2003, Darmstadt 2005). These authors do not report how these judgments were made, nor whether there was discrepancy in opinion in making these judgments.

Studies which assessed applicability described difficulty in making judgments about applicability of interventions in different settings than the settings where the primary studies were conducted (for example, Althabe 2008 describes difficulty in assessing applicability because the context and setting is different in Argentina than in other low and middle income countries). For judging the relevance and applicability to LMIC, there was limited evidence on real-world effectiveness in LMIC, thus the authors relied on efficacy data from systematic reviews as well as expert opinion (Darmstadt 2005). For example, some interventions require ac- cess to highly skilled professionals, equipment or emergency transportation which may not be available in LMIC (Darmstadt 2009). For example, smoking cessation trials have almost all been conducted in high-income countries, and their applicability to low and middle income country settings is questioned because risk factors may be different for women in low and middle income countries (Yakoob 2009).

Advantages of judging applicability to disadvantaged populations and/or settings are that it makes use of the best available evidence to make judgments that can be used to inform policies. Disadvantages are that the judgment of applicability and equity are extremely challenging and requires content expertise, knowledge of LMIC settings and methodological knowledge (Althabe 2008). Furthermore, assessing applicability does not assess the likely magnitude of effects and, since LMIC settings are extremely heterogeneous, the judgments required for these checklists need to be framed for specific settings.

\section{Comparison against the "seven rules of when to believe a subgroup analysis"}

For the eleven methodology studies which reported subgroup analyses in SRs across a PROGRESS-Plus factor, we assessed whether these analyses met the Oxman and Guyatt seven credibility criteria of when to believe a subgroup analysis (Table 3) (Oxman 1992). We also assessed two additional criteria suggested by Rothwell that subgroup analyses should be tested with a subgroup by treatment interaction and that randomization of trials should be stratified across the intended subgroup analyses (Rothwell 2005). The eleven methodology studies provided insufficient data to assess seven out of nine criteria. Five studies provided a rationale to support the subgroup analyses, four studies described an a priori hypothesis, three studies reported statistical or clinically important differences, without details on the type of statistical test. None of these methodological studies described whether the differences assessed by subgroup analyses were due to differences in absolute effects (e.g. because of higher baseline risk in disadvantaged groups) or relative effects (e.g. because of different mechanisms of action).

\section{Factors associated with differences in effects}

None of the methodological studies described factors that might plausibly be associated with differences in effects across PROGRESS-Plus.

\section{DISCUSSION}

Systematic reviews represent an opportunity for increasing the ability to detect subgroup differences because they include studies conducted in diverse settings and populations(Glasziou 2002). 
These systematic reviews can increase the confidence in their subgroup analyses by reporting the rationale and methods in sufficient detail (Oxman 1992; Rothwell 2005). Measurement of effects on health inequalities is an active field of research, with over half of the included studies published in the last two years.

We identified four methods to assess effects on health equity in cohorts of systematic reviews: 1) describe populations in SRs; 2) describe populations in primary studies (e.g. randomized controlled trials or cohort studies); 3) analysis of different effects (benefit or harm); and 4) applicability assessment. However, the poor availability of data, both in primary studies and systematic reviews, for all of these approaches limits their usefulness.

The descriptive and analytic methods used in these methodology studies (described above) require data on outcomes stratified for specific populations across PROGRESS-Plus to assess effects in these populations. However, a lack of population-specific stratified outcome data does not mean that an intervention will not be effective in other populations (e.g. because primary studies have not been conducted in these populations or data has not been reported in the primary studies or the systematic reviews). For example, vaccination is expected to be effective in diverse populations, across a range of baseline risk and settings. For interventions tested in relatively advantaged populations, clinical epidemiology principles suggest that the relative risk reduction will remain the same across differences in baseline risk (Anderson 2005). Thus, the absolute risk reduction is expected to be larger for populations with a higher baseline risk. For example, therapeutic drug monitoring was shown to be effective at improving adherence to antiretrovirals in clinical trials conducted exclusively in high-income countries. If the relative risk of 1.49 can be applied to low and middle income countries with higher HIV endemicity, a greater absolute effect may be achieved on population health (Kredo 2009).

None of these 34 empirical studies assessed what factors are associated with differences in effects on health equity. Identifying characteristics of interventions, population, comparison, setting, study design which are associated with effects on health equity could be used to inform a priori decisions to assess effects on health equity in systematic reviews and primary studies.

Descriptive and analytic approaches used by these methodology studies have the advantage of assessing whether an intervention has been tested in a specific disadvantaged population, which is appealing to practitioners and decision-makers deciding whether to implement an intervention in a specific population and setting. Analytic approaches have the advantage of providing an estimate of the magnitude of effect in either advantaged or disadvantaged populations, or both. However, we found few systematic reviews which conducted subgroup analyses, and none of them described the analyses in sufficient detail to assess the credibility of the findings, since they failed to report details on the seven Oxman and Guyatt credibility criteria (Oxman 1992). Updated guidelines on subgroup analyses suggest also assessing four more items: 1) consideration of baseline characteristics; 2) independence of the subgroup effect (i.e. the subgroup effect is not confounded by association with another factor); 3) a priori specification of the direction of effect; and 4) consistency across related outcomes (Sun 2010). We did not assess these four additional factors.

None of the systematic reviews which reported effects on health inequalities described whether these different effects were due to differences in absolute or relative effects. Differences in absolute effects are expected in groups with a higher baseline risk of the outcome. For example, women from low and middle income countries have a higher rate of maternal mortality, and might achieve a larger benefit in absolute terms from interventions such as having a skilled attendant at the birth than women in high-income countries with a very low maternal mortality. Differences in relative effects suggest that the mechanism of action of an intervention is different. For example, the relative effect of increases in tobacco price is greater in low income populations (Thomas 2008).

Judgment of applicability of evidence to disadvantaged populations and settings makes use of available evidence to inform decisions. Judging applicability or generalizability is used for making decisions about populations, interventions, comparisons, outcomes or settings beyond those studies in the systematic review and included trials. These methods have the potential to reduce needless replication of studies in different populations. Internationally recognized tools such as SIGN (SIGN 2008) and GRADE (Guyatt 2008, Guyatt 2008a) have the potential to increase the credibility of these judgments about directness of evidence to specific populations, if the judgments about directness are reported transparently. However, there is limited guidance provided by these tools on when evidence is sufficiently indirect to warrant downgrading quality. Applying these checklists is challenging and requires significant content, methodological and setting-specific expertise to judge whether: 1) the observed differences is a true differences or random error; 2) are there differences in absolute effects due to different prevalence of the condition,or 3) are there differences in relative effects due to differences in how the intervention is delivered or received. For example, lack of follow-up in settings with barriers to accessing regular care could lead to more serious adverse events if early signs of toxicity are missed. Applying these checklists is also challenging due to lack of data from settings of interest, and lack of data on the differences between settings in the primary studies and the setting to which the results will be applied. For example, the overviews of interventions to reduce stillbirths reported a lack of data from LMIC for most interventions, and raised questions about the differences in LMIC settings such as provider skill, availability of emergency transportation and access to clean delivery sites (Darmstadt 2009, Haws 2009, Yakoob 2009, Menezes 2009, Bhutta 2009). The reporting of how these judgments were made was inconsistent.

There is a lack of conceptual clarity regarding the definition of 
health equity. Only three out of 34 studies defined health equity explicitly. Use of the terms gender and sex in these studies conflicted with internationally accepted definitions, i.e. that sex refers to biological differences and gender refers to cultural and socially determined roles of males and females (Spitzer 2008).

Six out of 34 studies involved collaboration of the Cochrane Equity Methods Group. These studies analyzed cohorts of Cochrane reviews, which may be limited in their ability to detect subgroup differences since Cochrane reviews tend to contain fewer trials (median 8 studies) than other systematic reviews (Moher 2007). Furthermore, Cochrane reviews tend to assess efficacy questions where the effect size might be less likely to vary in different populations than for implementation questions which are more likely to be assessed by pragmatic trials (Thorpe 2009). None of the methodology studies assessed systematic reviews which focus on educational, legal and educational interventions; such as those from the Campbell Collaboration.

We identified six studies which assessed inequalities in health behaviours or determinants of health such as tobacco cessation and uptake of childhood vaccination (Jepson 2010, Bambra 2010, Main 2008, Ogilvie 2004, Shea 2009, Vergidis 2009). It is well known that inequalities in health behaviours do not fully explain inequalities in health status (Marmot 2008). Because the methodological challenges of assessing differences in health behaviours and health outcomes are similar, we included these studies in this review.

We used a rigorous and transparent process to identify and describe methods for assessing effects on health equity in systematic reviews, following up to date guidelines from the Cochrane Collaboration Handbook (Cochrane Handbook 2009). We used a structured approach to extracting and assessing factors across which health inequity may exist: the acronym PROGRESS-Plus, accepted by the Campbell and Cochrane Equity methods group. We used a team of five people to extract data, and each study was assessed by at least two review authors. We used the PRISMA reporting guidelines to facilitate replicability (Moher 2009). There is a risk that we have missed some relevant studies since methodological studies of cohorts of systematic reviews are not well-indexed and also since we decided to apply a geographic filter (Grobler 2008). We addressed this by using a comprehensive search strategy of both health and non-health databases, that imposed no limits on study design based on pilot-testing of the search strategy and review by a librarian scientist (JM) (Sampson 2008). We also searched reference lists and used SCOPUS to identify citations of included studies. Three out of 20 of the included studies were published as abstracts (Tsikata 2003; Nasser 2007) or reports (Ball 2002) and one included study was identified by contact with experts (Bambra 2010). Furthermore, one ongoing study and one excluded study were identified by contacting authors of included studies.

A limitation of this systematic review is that we did not include individual systematic reviews. We decided a priori that their inclusion could lead to bias since they may be less likely to report analyses of effects on health equity if none were found.

Another limitation of this review is that systematic reviews are dependent on the availability of data in primary studies. This systematic review did not assess whether data was available in primary studies nor the different biases which determine the representation and reporting of different populations and stratified analyses in primary research. Some of the authors of this review team are authors on empirical studies included in this review (PT, MP, EK, EU, VW, JM, GW). We sought to minimize the possible bias of analysis and synthesis of these studies by having those studies extracted by a review author who was not a co-author (JdM or MB).

\section{A U THORS' CONCLUSIONS}

\section{Implication for systematic reviews and evaluations of healthcare}

There is a need for improved clarity regarding definition of health equity in systematic reviews which focus on effects of interventions in disadvantaged populations. The final report of the WHO CSDH (Marmot 2008) provides recommendations on how to assess and define social determinants of health and health equity. Systematic reviews need to improve reporting of population and setting characteristics of primary trials in systematic reviews, to facilitate judgments about applicability, both for disadvantaged populations, as well as other populations not included in the primary trials. Regarding subgroup analyses, there is a need to improve the conduct and reporting of subgroup analyses both in systematic reviews and primary studies to improve their credibility. These include the need for description of the rationale for subgroup analyses, assessment of clinical importance of subgroup differences, description of whether differences between groups are due to differences in absolute effects or relative effects. Systematic review authors can consult the Campbell and Cochrane Equity Methods group for further guidance on analytic approaches to assessing differences in effects of interventions in disadvantaged populations. If systematic reviews discuss applicability, they need to transparently report the details of how these judgments were made, including who made them (e.g. whether a consensus approach was used).

\section{Implication for methodological research}

Methodological guidance, based on empirical data about the advantages and disadvantages of different approaches, is needed on how to assess effects on health equity in systematic reviews.

This systematic review identifies five areas for future research. Firstly, there is a need for methodological research to identify factors associated with differences in absolute and relative effects to 
improve our understanding of the rationale for exploring subgroup effects. Secondly, there is a need for methodological studies to assess the extent to which subgroup analyses can be used to assess intervention-generated inequalities. For example, individual patient data meta-analysis of individual level factors can be compared with study-level subgroup analyses to assess consistency of the findings across and within studies (Sutton 2008). Thirdly, there is a need for methodological studies to assess differences in absolute and relative effects between advantaged and disadvantaged populations, and specifically, how socioeconomic factors may drive the effects of interventions across groups.. Fourthly, methodological research on how to make judgments about applicability (e.g. to assess effects of providing structured guidance) on both the replicability of the judgments as well as their relationship to actual examples of applying interventions in different populations and settings. Fifthly, methodological research on how to consider the role of local context at different levels would be useful in considering contextual factors such as sociopolitical climate when judging applicability.

\section{ACKNOWLEDGEMENTS}

The authors would like to acknowledge David Moher, Dean Fergusson, and Jennifer Tetzlaff who provided comments in the development of this protocol as part of a graduate level systematic review course at the University of Ottawa. The authors would like to thank Jordi Pardo Pardo for his tireless and enthusiastic support to complete this review and for assistance in assessing two Spanish articles for inclusion.

\section{R E F E R E N C E S}

\section{References to studies included in this review}

\section{Adamek 2008 \{published data only\}}

Adamek ME, Slater GY, Adamek Margaret E, Slater Greta Yoder. Depression and anxiety. Journal of Gerontological Social Work 2008;50 Suppl 1:153-89.

Althabe 2008 \{published data only\} Althabe F, Bergel E, Cafferata ML, Gibbons L, Ciapponi A, Aleman A, et al.Strategies for improving the quality of health care in maternal and child health in low- and middleincome countries: an overview of systematic reviews. Paediatric and Perinatal Epidemiology 2008;22 Suppl 1: 42-60.

Ball 2002 \{published data only\} Ball L. Low birth weight: exploring an enigma of failure. British Journal of Midwifery 2004;12(6):374-9.

Ball L, Kirkham M. Low birth weight in Sheffield. A review of interventions and their effectiveness. Sheffield, UK: University of Sheffield, Women's Informed Childbearing and Health Research Group, 2002:1-57.

Bambra 2010 \{published data only\}

Bambra C, Gibson M, Sowden A, Wright K, Whitehead M, Petticrew M. Tackling the wider social determinants of health and health inequalities: evidence from systematic reviews. Journal of Epidemiology \& Community Health 2010; 64:284-291.

Bambra C, Gibson M, Sowden AJ, Wright K, Whitehead M, Petticrew M. Working for health? Evidence from systematic reviews on the effects on health and health inequalities of organisational changes to the psychosocial work environment. Preventive Medicine 2009;48(5): 454-61.

Barros 2010 \{published data only\} Barros FC, Bhutta ZA, Batra M, Hansen TN, Victora CG, Rubens CE, et al.Global report on preterm birth and stillbirth ( 3 of 7): evidence for effectiveness of interventions. BMC Pregnancy and Childbirth 2010;10(Suppl 1):S3.

Bartels 2003 \{published data only\}

Bartels SJD. Evidence-based practices in geriatric mental health care: An overview of systematic reviews and metaanalyses. Psychiatric Clinics of North America 2003;26(4): Dec.

Bhutta 2008 \{published data only\} Bhutta ZA, Ali S, Cousens S, Ali TM, Haider BA, Rizvi A, et al.Alma-Ata: Rebirth and Revision 6 Interventions to address maternal, newborn, and child survival: what difference can integrated primary health care strategies make?. The Lancet 2008;372(9642):972-89.

Bhutta 2008a \{published data only\}

Bhutta Zulfiqar A, Ahmed Tahmeed, Black Robert E, Cousens Simon, Dewey Kathryn, Giugliani Elsa, et al.What works? Interventions for maternal and child undernutrition and survival. The Lancet 2008;371(9610):417-40.

Bhutta 2009 \{published data only\}

Bhutta ZA, Darmstadt GL, Haws RA, Yakoob MY, Lawn JE. Delivering interventions to reduce the global burden of stillbirths. Neonatal Intensive Care 2009;22(7):39-43.

Browne 2004 \{published data only\}

Browne Gina, Gafni Amiram, Roberts Jacqueline, Byrne Carolyn, Majumdar Basanti. Effective/Efficient Mental Health Programs for School-Age Children: A Synthesis of Reviews. Social Science and Medicine 2004;58(7):13671384, Apr.

\section{Chopra 2008 \{published data only\}} Chopra M, Munro S, Lavis JN, Vist G, Bennett S. Effects of policy options for human resources for health: an analysis of systematic reviews. Lancet 2008;371(9613):668-774. 
D'Souza 2004 \{published data only\}

D'Souza L, Garcia J. Improving services for disadvantaged childbearing women. Child: Care, Health \& Development 2004;30(6):599-611.

Darmstadt 2005 \{published data only\} Darmstadt GL, Bhutta ZA, Cousens S, Adam T, Walker N, de Bernis L. Evidence-based, cost-effective interventions: how many newborn babies can we save?. Lancet 2005;365 (9463):977-88.

Darmstadt 2009 \{published data only\}

Darmstadt Gary, Yakoob Mohammad, Haws Rachel, Menezes Esme, Soomro Tanya, Bhutta Zulfiqar. Reducing stillbirths: interventions during labour. BMC Pregnancy and Childbirth 2009;9(Suppl 1):S6.

Doull 2010 \{published and unpublished data\}

Doull M, Runnels VE, Tudiver S, Boscoe M. Appraising the evidence: applying sex and gender-based analysis (SGBA) to Cochrane systematic reviews on cardiovascular diseases. Journal of Women's Health 2010;19(5):997-1003.

Tudiver S, deBoscoe M, Runnels V, Doull M. Context Matters: Applying Sex and Gender-based Analysis to Cochrane Reviews. 6th Annual Canadian Cochrane Symposium-- March 6-7, 2008. Edmonton, Alberta, Canada: Cochrane Canada, 2008.

Haws 2009 \{published data only\}

Haws Rachel, Yakoob Mohammad, Soomro Tanya, Menezes Esme, Darmstadt Gary, Bhutta Zulfiqar. Reducing stillbirths: screening and monitoring during pregnancy and labour. BMC Pregnancy and Childbirth 2009;9(Suppl 1):S5.

Jepson 2010 \{published data only\}

Jepson RG, Harris FM, Platt S, Tannahill C. The effectiveness of interventions to change six health behaviours: A review of reviews. BMC Public Health 2010; 10:538.

Johnson 2003 \{published data only\}

Johnson SM, Karvonen CA, Phelps CL, Nader S, Sanborn BM. Assessment of analysis by gender in the Cochrane reviews as related to treatment of cardiovascular disease. [Review] [48 refs]. Journal of Women's Health 2003;12(5): 449-57.

Jones 2003 \{published data only\}

Jones G, Steketee RW, Black RE, Bhutta ZA, Morris SS. How many child deaths can we prevent this year?. Lancet 2003;362 (9377):65-71.

Lewin 2008 \{published data only\}

Lewin S, Lavis JN, Oxman AD, Bastias G, Chopra M, Ciapponi A, et al.Supporting the delivery of cost-effective interventions in primary health-care systems in low-income and middle-income countries: an overview of systematic reviews. Lancet 2008;372(9642):928-39.

Main 2008 \{published data only\}

Main C, Thomas Sian, Ogilvie D, Stirk L, Petticrew $\mathrm{M}$, Whitehead M, et al.Population tobacco control interventions and their effects on social inequalities in smoking: placing an equity lens on existing systematic reviews. BMC Public Health 2008;8:178. [DOI: 10.1186/

1471-2458-8-178]

Menezes 2009 \{published data only\}

Menezes EVY, Yakoob MY, Soomro T, Haws RA, Darmstadt GL, Bhutta ZA. Reducing stillbirths: Prevention and management of medical disorders and infections during pregnancy. BMC Pregnancy and Childbirth 2009;9(SUPPL. 1):S4.

Morrison 2004 \{published data only\} Morrison A, Wertheimer AI. Compilation of quantitative overviews of studies of adherence. Drug Information Journal 2004;38(2):197-210.

Nasser 2007 \{published and unpublished data\}

Nasser M Ortiz Z, Berenstein G, Garcì Dieguez M, Angel Exposito J, Pardo J. Guidelines for preparing Cochrane Reviews relevant to Developing Countries. XV Cochrane Colloquium 23-27 October. Sao Paulo, Brazil: Cochrane Collaboration, 2007.

Odierna 2009 \{published data only\}

Odierna DH, Bero LA. Systematic reviews reveal unrepresentative evidence for the development of drug formularies for poor and nonwhite populations. Journal of Clinical Epidemiology 2009;62(12):1268-78.

Ogilvie 2004 \{published data only\} Ogilvie D, Petticrew M. Reducing social inequalities in smoking: can evidence inform policy? A pilot study. Tob Control 2004;13(2):129-131.

Shea 2009 \{published data only\}

Shea Beverley, Andersson Neil, Henry David. Increasing the demand for childhood vaccination in developing countries: a systematic review. BMC International Health and Human Rights 2009;9(Suppl 1):S5.

Sherr 2009 \{published data only\} Sherr LMueller. Evidence-based gender findings for children affected by HIV and AIDS - A systematic overview. AIDS Care - Psychological and Socio-Medical Aspects of AIDS/HIV 2009;21(SUPPL. 1):2009.

Stewart 2006 \{published data only\}

Stewart D, Stavness C, King G, Antle B, Law M, Stewart Debra, et al.A critical appraisal of literature reviews about the transition to adulthood for youth with disabilities. Physical \& Occupational Therapy in Pediatrics 2006;26(4): 5-24.

Tsikata 2003 \{published data only\}

Tsikata S, Robinson V, Petticrew M, Kristjansson B, Moher D, McGowan J, et al.Do Cochrane systematic reviews contain useful information about health equity? [abstract]. XI.Cochrane Colloquium.Evidence, Health Care and Culture; Oct 26-31;. Barcelona., Spain: Cochrane Collaboration, 2003:77.

Tugwell 2008 \{published data only\}

Tugwell P, Maxwell L, Welch V, Kristjansson E, Petticrew $\mathrm{M}$, Wells $\mathrm{G}$, et al.Is health equity considered in systematic reviews of the Cochrane Musculoskeletal Group?. Arthritis Care and Research 2008;59(11):1603-10. 
Vergidis 2009 \{published data only\}

Vergidis PIF. Meta-analyses on Behavioral Interventions to Reduce the Risk of Transmission of HIV. Infectious Disease Clinics of North America 2009;23(2):June.

Viswanathan 2008 \{published data only\}

Viswanathan M, Viswanathan Meera. Tailoring systematic reviews to meet critical priorities in maternal health in the intrapartum period. [Review] [110 refs]. Paediatric and Perinatal Epidemiology 2008;22 Suppl 1:10-7.

Yakoob 2009 \{published data only\} Yakoob MYM, Menezes EV, Soomro T, Haws RA, Darmstadt GL, Bhutta ZA. Reducing stillbirths: Behavioural and nutritional interventions before and during pregnancy. BMC Pregnancy and Childbirth 2009;9(SUPPL. 1):S3.

\section{References to studies excluded from this review}

\section{Ahmad 2010 \{published data only\}}

Ahmad N, Boutron I, Dechartres A, Durieux P, Ravaud P. Applicability and generalisability of the results of systematic reviews to public health practice and policy: A systematic review. Trials 2010;11:20.

\section{AHRQ 2010 \{published data only\}}

West SL, Gartlehner G, Mansfield AJ, Poole C, Tant E, Lenfestey N, Lux LJ, Amoozegar J, Morton SC, Carey TC, Viswanathan M, Lohr KN. Comparative effectiveness methods: clinical heterogeneity. Prepared for Agency of Healthcare Research and Quality, US Department of Health and Human Services 2010; Vol. Contract No. 290-2007-10056-I and Part II, issue AHRQ Publication No. 10-EHC-070-EF.

Barlow 2004 \{published data only\}

Barlow JH, Ellard DR, Barlow JH, Ellard DR. Psychoeducational interventions for children with chronic disease, parents and siblings: an overview of the research evidence base. [Review] [29 refs]. Child: Care, Health \& Development 2004;30(6):637-45.

Craig 2003 \{published data only\} Craig Leam A, Browne Kevin D, Stringer Ian. Treatment and sexual offense recidivism. Trauma \& Abuse: A Review Journal 2003;4(70):89-95.

Espinosa-Aguilar 2007 \{published data only\} Espinosa-Aguilar Amilcar, Caraveo-Anduaga Jorge, Zamora-Olvera Miguel, Arronte-Rosales Alicia, KrugLlamas Ernesto, Olivares-Santos Roberto, et al.Clinical guideline for diagnosis and treatment of depression in elderly. [Spanish]. [References]. Salud Mental 2007;30(6): Nov-Dec.

Gaes 1999 \{published data only\}

Gaes Gerald G, Flanagan Timothy J, Motiuk Larry L. Adult correctional treatment. In: Michael Tonry, Joan Petersilia editor(s). Crime and Justice. Prisons. Vol. 26, Chicago: University of Chicago Press, 1999:361-426.
Gulmezoglu 1997 \{published data only\}

Gulmezoglu M, de Onis M, Villar J. Effectiveness of interventions to prevent or treat impaired fetal growth. Obstetrical \& Gynecological Survey 1997;52(2):139-49.

Thomas 2008 \{published data only\}

Thomas S, Fayter D, Misso K, Ogilvie D, Petticrew M, Sowden A, et al.Population tobacco control interventions and their effects on social inequalities in smoking: systematic review. [Review] [109 refs]. Tobacco Control 2008;17(4):230-7.

\section{References to ongoing studies}

\section{Panteli 2009 \{published data only}

Panteli D, Zentner A, Busse R. Equity and health technology assessment: a systematic review of the literature. www.mig.tu-berlin.de/fileadmin/a38331600/ 2010.lectures/Poster equity 2010.pdf. Dublin, Ireland: Health Technology Internatonal (HTAi) Annual Meeting (6-9 Jun 2010), 2010.

\section{Additional references}

58th World Health Assembly Resolution 58th World Health Assembly Resolution. World Health Organization 2008.

Adams 2005

Adams Jean, White Martin. When the population approach to prevention puts the health of individuals at risk. International Journal of Epidemiology 2005;34(1):40-3.

Anderson 2005

Anderson GM, Bronskill SE, Mustard CA, Culyer A, Alter DA, Manuel DG. Both clinical epidemiology and population health perspectives can define the role of health care in reducing health disparities. J Clin Epidemiol 2005; 58(8):757-62.

\section{Arblaster 1996}

Arblaster L, Lambert M, Entwistle V, Forster M, Fullerton $\mathrm{D}$, Sheldon T, et al.A systematic review of the effectiveness of health service interventions aimed at reducing inequalities in health. Journal of Health Services Research \& Policy 1996; 1(2):93-103.

Berlin 1997

Berlin JA, Miles CG, Crigliano MD. Does blinding of readers affect the results of meta-analyses? Results of a randomized trial. Lancet 1997;350(9072):185-6.

Chan 2004

Chan AW, Hrobjartsson A, Haahr MT, Gotzsche PC, Altman DG. Empirical evidence for selective reporting of outcomes in randomized trials: comparison of protocols to published articles. JAMA 2004;291(20):2457-65.

Cochrane Handbook 2009

HIggins JPT, Green S (editors). Cochrane Handbook for Systematic Reviews of Interventions. Available from www.cochrane-handbook.org.. Vol. Version 5.0.2 [updated September 2009], The Cochrane Collaboration, 2009. 


\section{Curran 2006}

Martin Curran M, MacLehose HG. Community animal health services for improving household wealth and health status of low income farmers. Cochrane Database of Systematic Reviews 2006, Issue 2. [DOI: 10.1002/ 14651858.CD003049.pub2]

European Organization for Nuclear Research 2003 European Organization for Nuclear Research (CERN). The Role of Science in the Information Society [conference]. 2003 December 8-9; Geneva. http://rsis.web.cern.ch/rsis/ 00Themes/01Health/Health.html (accessed 15 April 2009).

Evans 2003

Evans T, Brown H. Road traffic crashes: operationalizing equity in the context of health sector reform. Inj Control Saf Promot 2003;10:11-12.

\section{Gakidou 2010}

Gakidou E, Cowling K, Lozano R, Murray CJL. Increased educational attainment and its effect on child mortality in 175 countries between 1970 and 2009: a systematic analysis. Lancet 2010;376:959-974.

\section{Gastwirth 1972}

Gastwirth JL. The estimation of the Lorenz curve and Gini index. Review of Economics and Statistics 1972;54:306-16.

\section{Gepkens 1996}

Gepkens A, Gunning-Schepers LJ. Interventions to reduce socioeconomic health differences: A review of the international literature. European Journal of Public Health 1996;6(3):218-26.

\section{Glasziou 2002}

Glasziou PP, Sanders SL. Investigating causes of heterogeneity in systematic reviews. Statistics in Medicine 2002;21(11):1503-11.

\section{Grobler 2008}

Grobler L, Pienaar E, Siegfried N, Eisinga A. Challenges of developing a geographic search filter to identify randomized controlled trials in Africa: finding the optimal balance between sensitivity and precision. 16th International Cochrane Colloquium. Freiburg, Germany: Cochrane Collaboration, 3-7 October 2008.

\section{Guyatt 2008}

Guyatt GH, Oxman AD, Kunz R, Falck-Ytter Y, Vist GE, Liberati A, et al.Going from evidence to recommendations. BMJ 2008;336(1468-5833 (Electronic), 0959-535X (Linking), 7652):1049-51.

\section{Guyatt 2008a}

Guyatt GH, Oxman AD, Kunz R, Vist GE, Falck-Ytter Y, Schunemann HJ. What is "quality of evidence" and why is it important to clinicians?. BMJ 2008;336(1468-5833 (Electronic), 0959-535X (Linking), 7651):995-8.

\section{Higgins 2008}

Higgins JPT, Altman DG. Chapter 8: Assessing risk of bias in included studies. In: Higgins JPT, Green S editor(s). Cochrane Handbook for Systematic Reviews of Interventions. Version 5.0.1 (updated September 2008). Oxford, UK:
The Cochrane Collaboration, 2008. Available from www.cochrane-handbook.org.

\section{Kavanagh 2008}

Kavanagh J, Oliver S, Lorenc T. Reflections in developing and using PROGRESS-Plus. Equity Update. http://www.equity.cochrane.org/Files/ Equity Update'Vol2 Issue1.pdf, 2008; Vol. 2:1-3.

\section{Kawachi 1999}

Kawachi I. Social capital and community effects on population and individual health. Annals of the New York Academy of Sciences 1999;896:120-30.

\section{Keppel 2005}

Keppel K, Pamuk E, Lynch J, Carter-Pokras O, Kim $\mathrm{I}$, Mays V, et al.Methodological issues in measuring health disparities. Washington DC: National Center for Health Statistics; 2005. Vital Health Statistics Series 2, Number 141. National Centre for Health Statistics, http:// www.cdc.gov/nchs/data/series/sr'02/sr02'141.pdf.

\section{Koolman 2004}

Koolman X, van Doorslaer E. On the interpretation of a concentration index of inequality. Health Economics 2004; 13(7):649-56.

\section{Kredo 2009}

Kredo T, Van der Walt JS, Siegfried N, Cohen K. Therapeutic drug monitoring of antiretrovirals for people with HIV. Cochrane Database of Systematic Reviews 2009, Issue 3.

\section{Lavis 2005}

Lavis JN, Davies H, Oxman A, Denis JL, Golden-Biddle K, Ferlie E. Towards systematic reviews that inform health care management and policy-making. Journal of Health Services Research \& Policy 2005;10(Suppl 1):35-48.

Lavis 2006

Lavis JN, Davies HTO, Gruen RL. Working within and beyond the Cochrane Collaboration to make systematic reviews more useful to healthcare managers and policy makers. Healthcare Policy 2006;1(2):21-33.

Lavis 2009

Lavis JN. How Can We Support the Use of Systematic Reviews in Policymaking?. PLoS Med 2009;6(11): e1000141.

\section{Marmot 2008}

Marmot M, Friel S, Bell R, Houweling TA, Taylor S, Commission on Social Determinants of Health. Closing the gap in a generation: health equity through action on the social determinants of health. Lancet 2008;372(9650): 1661-9.

\section{McGowan 2003}

McGowan J, Robinson V, Kristjansson B, Petticrew M, Tugwell P. Identifying studies that include issues of equity for inclusion in Cochrane Reviews. XI Cochrane Colloquium: Evidence, Health Care and Culture. Barcelona, Spain: Cochrane Collaboration, 2003:71. [CENTRAL: 5122] 
Moher 2007

Moher D, Tetzlaff J, Tricco AC, Sampson M, Altman DG. Epidemiology and reporting characteristics of systematic reviews. PLoS Med 2007;4(3):e78.

\section{Moher 2009}

Moher D, Liberati A, Tetzlaff J, Altman DG, PRISMA Group. Preferred reporting items for systematic reviews and meta-analyses: the PRISMA statement. BMJ 2009;339: b2535.

Ogilvie 2004

Ogilvie D, Petticrew M. Reducing social inequalities in smoking: can evidence inform policy? A pilot study. Tobacco Control 2004;13(2):129-31.

\section{Oxman 1992}

Oxman AD, Guyatt GH. A consumer's guide to subgroup analyses. Annals of Internal Medicine 1992;116(1):78-84.

Petticrew 2004

Petticrew M, Whitehead M, Macintye SJ, Graham H, Egan M. Evidence for public health policy on inequalities: 1 : the reality according to policymakers. Journal of Epidemiology and Community Health 2004;58(10):811-6.

Pope 2006

Pope C, Mays N, Popay J. Informing policy making and management in healthcare: The place for synthesis. Healthcare Policy 2006;1(2):43-8.

Role of Science in the Information Society

Role of Science in the Information Society. Role of Science in Information Society 2008.

Rothwell 2005

Rothwell PM. Treating individuals 2. Subgroup analysis in randomised controlled trials: importance, indications, and interpretation. Lancet 2005;365(9454):176-86.

\section{Sachs 2001}

Sachs JD. Macroeconomics and health: investing in health for economic development. Geneva, Switzerland: World Health Organization; 2001. http://whqlibdoc.who.int/ publications/2001/924154550X.pdf (accessed 15 April 2009). Geneva: World Health Organization.

\section{Sampson 2008}

Sampson M, McGowan J, Lefebvre C, Moher D, Grimshaw J. PRESS: peer review of electronic search strategies. Ottawa: Canadian Agency of Drugs and Technology for Health; 2008. Ottawa: Canadian Agency of Drugs and Technology for Health (CADTH).

\section{SIGN 2008}

Scottish Intercollegiate Guidelines Network. SIGN 50: A guideline developer's handbook, Available at http: I/www.sign.ac.uk/pdfsign50.pdf. Edinburgh: Scottish Intercollegiate Guidelines Network, 2008.

\section{Spitzer 2008}

Spitzer DL. Gender and Sex-Based Analysis in Health Research: A Guide for CIHR Researchers and Reviewers. Ottawa: Canadian Institutes of Health Research, 2008.
Sun 2010

Sun X, Briel M, Walter SD, Guyatt GH. Is a subgroup effect believable? Updating criteria to evaluate the credibility of subgroup analyses. British Medical Journal 2010;340:c117.

Sutton 2008

Sutton AJ, Kendrick D, Coupland CAC. Meta-analysis of individual- and aggregate-level data. Statistics in Medicine 2008;27(5):651-69.

\section{Thomas 2008}

Thomas S, Fayter D, Misso K, Ogilvie D, Petticrew M, Sowden A, Whitehead M, Worthy G. Population tobacco control interventions and their effects on social inequalities in smoking: systematic review. Tobacco Control 2008;17(4): 230-7.

\section{Thompson 2005}

Thompson SG, Higgins JP. Treating individuals 4: can meta-analysis help target interventions at individuals most likely to benefit?. Lancet 2005;365(9456):341-6.

Thorpe 2009

Thorpe KE, Zwarenstein M, Oxman AD, Treweek S, Furberg CD, Altman DG, et al.A pragmatic-explanatory continuum indicator summary (PRECIS): a tool to help trial designers. Journal of Clinical Epidemiology 2009;62(5): 464-75.

Tsikata 2003

Tsikata S, Robinson V, Petticrew M, Kristjansson B, Moher D, McGowan J, et al.Do Cochrane systematic reviews contain useful information about health equity? . XI Cochrane Colloquium: Evidence, Health Care and Culture; October 26-31;. Barcelona, Spain: Cochrane Collaboration, 2003.

\section{Tugwell 2006}

Tugwell P, Petticrew M, Robinson V, Kristjansson E, Maxwell L, Cochrane Equity Field Editorial Team. Cochrane and Campbell Collaborations, and health equity. Lancet 2006;367(9517):1128-30.

Wagstaff 2005

Wagstaff A, Waters $\mathrm{H}$. How were the reaching the poor studies done?. In: Gwatkin DR, Wagstaff A, Yazbeck AS editor(s). Reaching the poor with health, nutrition and population services: What works, what doesn't and why. Washington DC: The World Bank, 2005:27-46.

\section{Whitehead 1992}

Whitehead M. The concepts and principles of equity and health. International Journal of Health Services 1992;22(3): 429-45.

\section{World Bank}

The Concentration Index. Washington DC: The World Bank. Quantitative techniques for health equity analysis - Technical note \#7. http://siteresources.worldbank.org/ EXTEDSTATS/Resources/3232763-1171296378756/ concentration.pdf (accessed 15 April 2009).

\section{World Health Report 2008}

World Health Organization. The world health report 2008 : primary health care now more than ever. Geneva, 
Switzerland: World Health Organization; 2008. http:// www.who.int/whr/2008/whr08 en.pdf (accessed 15 April 2009). Geneva: World Health Organization.

You 2010

You D, Jones G, Hill K, Wardlaw T, Chopra M. Levels and trends in child mortality, 1990-2009. Lancet 2010;376: 932-933.

* Indicates the major publication for the study 


\section{CHARACTERISTICS OF STUDIES}

\section{Characteristics of included studies [ordered by study ID]}

\section{Adamek 2008}

\begin{tabular}{|c|c|c|}
\hline Methods & \multicolumn{2}{|c|}{ Meta-analyses of psychosocial or psychological interventions for older adults $(50+)$} \\
\hline Data & \multicolumn{2}{|l|}{ Plus- Age } \\
\hline Comparisons & \multicolumn{2}{|l|}{ Targeted } \\
\hline Outcomes & \multicolumn{2}{|l|}{16 systematic reviews } \\
\hline Equity definition & \multicolumn{2}{|l|}{ Equity not defined } \\
\hline Is judgment of equity made, if so, how? & \multicolumn{2}{|c|}{ Misdiagnosis of older people with depression is described as "needless" } \\
\hline $\begin{array}{l}\text { Rationale for assessing PROGRESS-Plus } \\
\text { dimension }\end{array}$ & \multicolumn{2}{|c|}{$\begin{array}{l}\text { Misdiagnosis of mental health and addiction disorders in older people due to discrimi- } \\
\text { nation based on age }\end{array}$} \\
\hline \multicolumn{3}{|l|}{ Notes } \\
\hline \multicolumn{3}{|l|}{ Risk of bias } \\
\hline Item & Authors' judgement & Description \\
\hline Selection bias? & Yes & $\begin{array}{l}\text { Comprehensive search for reviews focusing } \\
\text { on psychosocial or psychological interven- } \\
\text { tions for people } 50 \text { years of age or older }\end{array}$ \\
\hline Detection bias? & Unclear & $\begin{array}{l}\text { Methods for extracting details from SRs } \\
\text { were not described }\end{array}$ \\
\hline
\end{tabular}

\section{Althabe 2008}

\begin{tabular}{l|l}
\hline Methods & $\begin{array}{l}\text { To systematically analyse the results of systematic reviews of strategies for improving the } \\
\text { quality of care, where these strategies are relevant to maternal and child health (MCH) } \\
\text { in developing countries }\end{array}$ \\
\hline Data & Plus-LMIC \\
\hline Comparisons & Targeted \\
\hline Outcomes & 23 systematic reviews \\
\hline Equity definition & Equity not defined, but authors used the SUPPORT equity checklist
\end{tabular}


Althabe 2008 (Continued)

Is judgment of equity made, if so, how?

Rationale for assessing PROGRESS-Plus dimension
Authors judged equality, defined as equitable access to the strategies for the most disadvantaged health providers, and for the most vulnerable women and children

Need to appraise applicability and relevance of quality improvement strategies in LMIC to reduce health inequalities in maternal and child health

Notes

\section{Risk of bias}

\begin{tabular}{lll}
\hline Item & Authors' judgement & Description \\
\hline Selection bias? & Yes & $\begin{array}{l}2 \text { independent reviewers assessed SRs } \\
\text { against explicit inclusion criteria }\end{array}$ \\
\hline Detection bias? & Yes & $\begin{array}{l}\text { 2 independent reviewers extracted data us- } \\
\text { ing explicit extraction form }\end{array}$ \\
\hline
\end{tabular}

Ball 2002

Methods

\begin{tabular}{l|l}
\hline Data & SES, race/ethnicity, occupation \\
\hline Comparisons & Targeted \\
\hline Outcomes & 19 systematic reviews \\
\hline Equity definition & Equity not defined \\
\hline Is judgment of equity made, if so, how? & Health inequalities described as deeply entrenched and generational \\
\hline $\begin{array}{l}\text { Rationale for assessing PROGRESS-Plus } \\
\text { dimension }\end{array}$ & $\begin{array}{l}\text { To assess which interventions have the greatest positive impact on prevention of low } \\
\text { birth weight which is concentrated in families living in poverty and deprivation }\end{array}$ \\
\hline Notes & \\
\hline
\end{tabular}

\section{Risk of bias}

\begin{tabular}{|c|c|c|}
\hline Item & Authors' judgement & Description \\
\hline Selection bias? & Unclear & $\begin{array}{l}\text { Inclusion criteria not clear - article de- } \\
\text { scribed as review of reviews- papers related } \\
\text { to low birth weight }\end{array}$ \\
\hline
\end{tabular}


Ball 2002 (Continued)

\begin{tabular}{|c|c|c|}
\hline Detection bias? & No & No description of how articles were selected \\
\hline
\end{tabular}

\begin{tabular}{|c|c|c|}
\hline \multicolumn{3}{|l|}{ Bambra 2010} \\
\hline Methods & \multicolumn{2}{|c|}{$\begin{array}{l}\text { To identify evidence on interventions to reduce health inequalities by acting on social } \\
\text { determinants of health }\end{array}$} \\
\hline Data & \multicolumn{2}{|c|}{ SES, gender/sex, race/ethnicity, age } \\
\hline Comparisons & \multicolumn{2}{|l|}{ Gap } \\
\hline Outcomes & \multicolumn{2}{|l|}{30 systematic reviews } \\
\hline Equity definition & \multicolumn{2}{|c|}{ Health equity not defined } \\
\hline Is judgment of equity made, if so, how? & \multicolumn{2}{|c|}{ No judgment by authors } \\
\hline $\begin{array}{l}\text { Rationale for assessing PROGRESS-Plus } \\
\text { dimension }\end{array}$ & \multicolumn{2}{|c|}{$\begin{array}{l}\text { To identify evidence on interventions to reduce health inequalities by acting on social } \\
\text { determinants of health }\end{array}$} \\
\hline \multicolumn{3}{|l|}{ Notes } \\
\hline \multicolumn{3}{|l|}{ Risk of bias } \\
\hline Item & Authors' judgement & Description \\
\hline Selection bias? & Yes & $\begin{array}{l}\text { Systematic search of electronic databases + } \\
\text { handsearching }\end{array}$ \\
\hline Detection bias? & Yes & $\begin{array}{l}2 \text { independent reviewers screened titles and } \\
\text { extracted specific data }\end{array}$ \\
\hline
\end{tabular}

\section{Barros 2010}

\begin{tabular}{|c|c|}
\hline Methods & $\begin{array}{l}\text { Overview of } 49 \text { interventions directed towards mothers before and during pregnancy } \\
\text { and childbirth to prevent preterm birth and stillbirth, rated using GRADE criteria for } \\
\text { relevance to LMIC }\end{array}$ \\
\hline Data & Plus-LMIC \\
\hline Comparisons & Targeted \\
\hline Outcomes & 43 systematic reviews \\
\hline Equity definition & Unacceptable proportion burden of stillbirths in LMIC \\
\hline Is judgment of equity made, if so, how? & Preterm births, stillbirths are avoidable with known interventions \\
\hline
\end{tabular}


Barros 2010 (Continued)

Rationale for assessing PROGRESS-Plus Highest burden of stillbirth and preterm birth is in LMIC dimension

Notes

Risk of bias

\begin{tabular}{l|l|l}
\hline Item & Authors' judgement & Description \\
\hline Selection bias? & Yes & $\begin{array}{l}\text { Searched electronic databases for meta- } \\
\text { analyses, trials and observational evidence. } \\
\text { Then, interventions included if there was: } \\
\text { 1) evidence available, 2) evidence of im- } \\
\text { pact, 3) requires low or no technology, 4) } \\
\text { can be or is used in LMICs and 5) applica- } \\
\text { ble to wide group of pregnant women }\end{array}$ \\
\hline Detection bias? & Unclear & $\begin{array}{l}\text { 32 interventions excluded due to: (a) the } \\
\text { available evidence was very limited; (b) } \\
\text { there was no evidence of an impact; (c) the } \\
\text { intervention requires high technology; (d) } \\
\text { the intervention is seldom used; (e) the in- } \\
\text { tervention was applicable to a small sub- } \\
\text { group of pregnant women. Number of sys- } \\
\text { tematic reviews excluded is not reported }\end{array}$ \\
\hline
\end{tabular}

Bartels 2003

\begin{tabular}{|c|c|}
\hline Methods & To assess geriatric-specific evidence-base for mental health care \\
\hline Data & Plus- age and mental health \\
\hline Comparisons & Targeted \\
\hline Outcomes & 23 systematic reviews \\
\hline Equity definition & Equity not defined \\
\hline Is judgment of equity made, if so, how? & Unmet need for age-appropriate evidence-based practice geriatric mental health care \\
\hline $\begin{array}{l}\text { Rationale for assessing PROGRESS-Plus } \\
\text { dimension }\end{array}$ & $\begin{array}{l}\text { Older adults with mental illness receive poorer quality of care (relative to younger people } \\
\text { with mental illness and older people without mental illness) due to likelihood of more } \\
\text { adverse effects and smaller magnitude of benefit for older adults with mental illness } \\
\text { because of cognition, physiological and social functioning changes }\end{array}$ \\
\hline
\end{tabular}

Notes

How effects on health equity are assessed in systematic reviews of interventions (Review) 
Bartels 2003 (Continued)

\section{Risk of bias}

\begin{tabular}{lll}
\hline Item & Authors' judgement & Description \\
\hline Selection bias? & Yes & $\begin{array}{l}\text { Systematic search of three electronic } \\
\text { databases, with specific inclusion criteria } \\
\text { (geriatric specific guidelines, evidence re- } \\
\text { views and meta-analyses) }\end{array}$ \\
\hline Detection bias? & No & $\begin{array}{l}\text { No description of how data was extracted } \\
\text { or by who }\end{array}$ \\
\hline
\end{tabular}

\section{Bhutta 2008}

\begin{tabular}{|c|c|c|}
\hline Methods & \multicolumn{2}{|c|}{$\begin{array}{l}\text { Systematic review of maternal, neonatal, child health interventions with the aim of iden- } \\
\text { tifying a mix of evidence-based interventions and best delivery strategies in developing } \\
\text { countries }\end{array}$} \\
\hline Data & \multicolumn{2}{|l|}{ LMIC } \\
\hline Comparisons & \multicolumn{2}{|l|}{ Targeted } \\
\hline Outcomes & \multicolumn{2}{|l|}{52 systematic reviews } \\
\hline Equity definition & \multicolumn{2}{|c|}{$\begin{array}{l}\text { No definition of equity. describe "moral imperative" to achieve MDG } 4 \text { and } 5 \text { goals on } \\
\text { maternal and child health }\end{array}$} \\
\hline Is judgment of equity made, if so, how? & \multicolumn{2}{|c|}{ No judgment of equity. } \\
\hline $\begin{array}{l}\text { Rationale for assessing PROGRESS-Plus } \\
\text { dimension }\end{array}$ & \multicolumn{2}{|c|}{ To deliver on MDGS for maternal and child health } \\
\hline \multicolumn{3}{|l|}{ Notes } \\
\hline \multicolumn{3}{|l|}{ Risk of bias } \\
\hline Item & Authors' judgement & Description \\
\hline Selection bias? & Unclear & $\begin{array}{l}\text { Systematic } \\
\text { search of electronic databases, unpublished } \\
\text { reports, UN agencies. Method of selecting } \\
\text { systematic reviews was not described }\end{array}$ \\
\hline Detection bias? & Yes & $\begin{array}{l}\text { Data was independently extracted by } 3 \text { re- } \\
\text { viewers using pre-designed forms }\end{array}$ \\
\hline
\end{tabular}


Bhutta 2008a

Methods

\begin{tabular}{l|l}
\hline Data & LMIC \\
\hline Comparisons & Targeted \\
\hline
\end{tabular}

Outcomes 26 systematic reviews

Equity definition

Is judgment of equity made, if so, how?

No judgment of equity. Authors state "virtually all stunting is avertable"

Rationale for assessing PROGRESS-Plus dimension

To identify effective interventions and the preventable burden if these interventions were available in LMIC

Notes

\section{Risk of bias}

\begin{tabular}{lll}
\hline Item & Authors' judgement & Description \\
\hline Selection bias? & Unclear & $\begin{array}{l}\text { Systematic search of electronic databases, } \\
\text { screening and selection not described }\end{array}$ \\
\hline Detection bias? & Unclear & Method of extracting data not described \\
\hline
\end{tabular}

Bhutta 2009

Methods

Systematic searches in electronic databases to identify systematic reviews, trials and observational studies of interventions for delivering interventions to reduce stillbirths by improving service supply and community demand

\begin{tabular}{ll}
\hline Data & LMIC \\
\hline Comparisons & Targeted \\
\hline Outcomes & 11 SRs [8 Cochrane, 3 non-Cochrane] \\
\hline
\end{tabular}

Equity definition

Stillbirth rates are higher in LMIC compared to HIC, and these disparities apply within countries since economically deprived communities have higher stillbirth rates due to disparities in risk factors and inequalities in access and quality of care. $98 \%$ of stillbirths occur in LMIC

Is judgment of equity made, if so, how?

Most stillbirths occur in LMIC and are associated with absent inadequate or delayed obstetric care, thus they are preventable 
Bhutta 2009 (Continued)

Rationale for assessing PROGRESS-Plus dimension
In low resource settings, cost, distance and time needed to access care are major barriers to uptake of antenatal and intrapartum services

Notes

Risk of bias

\begin{tabular}{|c|c|c|}
\hline Item & Authors' judgement & Description \\
\hline Selection bias? & Yes & $\begin{array}{l}\text { Selected according to specified inclusion } \\
\text { criteria that it reported rate of still births } \\
\text { and was a biologically plausible interven- } \\
\text { tion identified by systematic search of mul- } \\
\text { tiple databases }\end{array}$ \\
\hline Detection bias? & Unclear & $\begin{array}{l}\text { Unclear. Method of extracting data and } \\
\text { who performed data extraction was not } \\
\text { provided }\end{array}$ \\
\hline
\end{tabular}

Browne 2004

\begin{tabular}{l|l} 
Methods & To review effectiveness of interventions to improve mental health for children \\
\hline Data & SES, race/ethnicity, gender/sex, age \\
\hline Comparisons & Targeted \\
\hline Outcomes & 23 systematic reviews \\
\hline Equity definition & Health equity not defined \\
\hline Is judgment of equity made, if so, how? & Absence of resources and opportunities described as risk factor for mental health problems \\
\hline $\begin{array}{l}\text { Rationale for assessing PROGRESS-Plus } \\
\text { dimension }\end{array}$ & $\begin{array}{l}\text { Policy initiatives need to be developed to ensure sufficient funding and promote delivery } \\
\text { of effective programs to appropriate children at risk of poor mental health }\end{array}$ \\
\hline Notes & \\
\hline
\end{tabular}

\section{Risk of bias}

\begin{tabular}{|c|c|c|}
\hline Item & Authors' judgement & Description \\
\hline Selection bias? & Yes & $\begin{array}{l}\text { all systematic reviews identified by system- } \\
\text { atic search using predefined inclusion cri- } \\
\text { teria: mental health promotion initiatives } \\
\text { for children }\end{array}$ \\
\hline
\end{tabular}


Browne 2004 (Continued)

\begin{tabular}{l|l} 
Detection bias? & Yes $\quad$ used critical appraisal tool to extract data \\
\hline
\end{tabular}

\section{Chopra 2008}

Methods

To assess effects of policy options on equitable distribution of health workers in LMIC

\begin{tabular}{ll}
\hline Data & LMIC \\
\hline Comparisons & Targeted \\
\hline Outcomes & 28 systematic reviews \\
\hline
\end{tabular}

Equity definition

Health equity not defined: lack of health workers in remote/rural areas described as inequitable

Is judgment of equity made, if so, how? Inequitable distribution of health workers limits quality health care

Rationale for assessing PROGRESS-Plus Quality health care depends on sufficient health workers to deliver the care (e.g. in remote dimension areas), policy makers need evidence on effects of policy options on equitable health care

Notes

Risk of bias

\begin{tabular}{lll}
\hline Item & Authors' judgement & Description \\
\hline Selection bias? & Yes & $\begin{array}{l}\text { systematic search of electronic databases } \\
\text { with inclusion criteria + handsearching }\end{array}$ \\
\hline Detection bias? & Yes & $\begin{array}{l}\text { used structured forms, 2 reviewers ex- } \\
\text { tracted data }\end{array}$ \\
\hline
\end{tabular}

D'Souza 2004

Methods

Data SES

\begin{tabular}{ll}
\hline Comparisons & Targeted \\
\hline Outcomes & 5 systematic reviews \\
\hline Equity definition & Equity not defined \\
\hline Is judgment of equity made, if so, how? & poor health concentrated in low SES women
\end{tabular}

How effects on health equity are assessed in systematic reviews of interventions (Review)

Copyright $\odot 2010$ The Cochrane Collaboration. Published by John Wiley \& Sons, Ltd.

SES

To review evidence on improving perinatal outcomes for disadvantaged women 
D'Souza 2004 (Continued)

Rationale for assessing PROGRESS-Plus Poor health outcomes are concentrated in socially disadvantaged mothers dimension

Notes

Risk of bias

\begin{tabular}{|c|c|c|}
\hline Item & Authors' judgement & Description \\
\hline Selection bias? & Yes & $\begin{array}{l}\text { Systematic search in } 8 \text { electronic databases } \\
\text { for systematic reviews and studies on } 10 \text { dif- } \\
\text { ferent subgroups of disadvantaged women }\end{array}$ \\
\hline Detection bias? & Unclear & Methods for data extraction not described \\
\hline
\end{tabular}

Darmstadt 2005

\begin{tabular}{|c|c|}
\hline Methods & $\begin{array}{l}\text { Systematic review of the evidence on the efficacy and effectiveness of interventions with } \\
\text { the potential to reduce perinatal or neonatal mortality, or both. Our aim was to identify } \\
\text { interventions for use in low-income and middle-income countries- thus high cost tech- } \\
\text { nology interventions were excluded (e.g. ventilation) }\end{array}$ \\
\hline Data & LMIC \\
\hline Comparisons & Targeted \\
\hline Outcomes & 12 systematic reviews \\
\hline Equity definition & $\begin{array}{l}\text { Unacceptably high number of neonatal deaths that happen every year } \\
\text { ( } 4 \text { million), their inequitable distribution, the increasing proportion of child deaths that } \\
\text { take place in the neonatal period, and the importance of reducing neonatal } \\
\text { mortality to meet the Millennium Development Goal for child survival (MDG-4). Most } \\
\text { neonatal deaths occur at home in low-income and middle-income countries } \\
\text { against a backdrop of poverty, sub-optimum care seeking, and weak health systems }\end{array}$ \\
\hline Is judgment of equity made, if so, how? & $\begin{array}{l}\text { No description of equity. Neonatal deaths are described as avoidable, and disproportion- } \\
\text { ate burden is carried by LMIC }\end{array}$ \\
\hline $\begin{array}{l}\text { Rationale for assessing PROGRESS-Plus } \\
\text { dimension }\end{array}$ & Importance of reducing neonatal mortality to meet the MDG- 4 for child survival \\
\hline Notes & \\
\hline
\end{tabular}

Risk of bias

Item

Authors' judgement

Description

How effects on health equity are assessed in systematic reviews of interventions (Review) 


\section{Darmstadt 2005 (Continued)}

\begin{tabular}{|c|c|c|}
\hline Selection bias? & Unclear & $\begin{array}{l}\text { Searches for systematic reviews, trials } \\
\text { and observational studies in electronic } \\
\text { databases, search terms not provided, se- } \\
\text { lection criteria provided. No description of } \\
\text { who screened the titles or how it was done }\end{array}$ \\
\hline Detection bias? & Unclear & Data extraction methods not described \\
\hline
\end{tabular}

Darmstadt 2009

Methods

Systematic review of the published literature, searching PubMed and the Cochrane Library, of trials and reviews $(\mathrm{N}=230)$ that reported stillbirth or perinatal mortality outcomes for eight interventions delivered during labour

\begin{tabular}{ll}
\hline Data & LMIC \\
\hline Comparisons & Targeted \\
\hline Outcomes & 23 Cochrane reviews \\
\hline
\end{tabular}

Equity definition

Stillbirth rates are higher in LMIC compared to HIC, and these disparities apply within countries since economically deprived communities have higher stillbirth rates due to disparities in risk factors and inequalities in access and quality of care. $98 \%$ of stillbirths occur in LMIC

Is judgment of equity made, if so, how?

Most stillbirths occur in LMIC and are associated with absent, inadequate or delayed obstetric care, thus they are preventable

Rationale for assessing PROGRESS-Plus Low proportion of stillbirths in HIC suggests they are preventable dimension

Notes

Risk of bias

\begin{tabular}{l|l|l}
\hline Item & Authors' judgement & Description \\
\hline Selection bias? & Yes & $\begin{array}{l}\text { Selected according to specified inclusion } \\
\text { criteria that it report rate of still births } \\
\text { and was a biologically plausible interven- } \\
\text { tion identified by systematic search of mul- } \\
\text { tiple databases }\end{array}$ \\
\hline Detection bias? & Unclear & Method of extracting data and who per- \\
& formed data extraction was not provided \\
\hline
\end{tabular}


Doull 2010

\begin{tabular}{|c|c|c|}
\hline Methods & \multicolumn{2}{|c|}{$\begin{array}{l}\text { Determine whether and how sex and gender are addressed in a sample of Cochrane } \\
\text { systematic reviews in cardiovascular disease }\end{array}$} \\
\hline Data & \multicolumn{2}{|c|}{ Gender and sex based analysis } \\
\hline Comparisons & \multicolumn{2}{|l|}{ Gap } \\
\hline Outcomes & \multicolumn{2}{|l|}{38 Cochrane SRs } \\
\hline Equity definition & \multicolumn{2}{|l|}{ not defined } \\
\hline Is judgment of equity made, if so, how? & \multicolumn{2}{|l|}{ not done } \\
\hline $\begin{array}{l}\text { Rationale for assessing PROGRESS-Plus } \\
\text { dimension }\end{array}$ & \multicolumn{2}{|c|}{$\begin{array}{l}\text { Research shows sex and gender are relevant in cardiovascular disease risk factors, but } \\
\text { quality of evidence remains weak for many }\end{array}$} \\
\hline \multicolumn{3}{|l|}{ Notes } \\
\hline \multicolumn{3}{|l|}{ Risk of bias } \\
\hline Item & Authors' judgement & Description \\
\hline Selection bias? & Yes & $\begin{array}{l}\text { Random sample of } 1 / 3 \text { of reviews from } \\
\text { Cochrane heart, hypertension and periph- } \\
\text { eral vascular disease review groups }\end{array}$ \\
\hline Detection bias? & Yes & $\begin{array}{l}\text { Data extracted using pre-tested form by } 1 \\
\text { research assistant }\end{array}$ \\
\hline
\end{tabular}

Haws 2009

Methods

This paper reviews available published evidence for the impact of 14 screening and monitoring interventions in pregnancy on stillbirth, including identification and management of high-risk pregnancies, advanced monitoring techniques, and monitoring of labour

\begin{tabular}{ll}
\hline Data & LMIC \\
\hline Comparisons & Targeted \\
\hline Outcomes & 23 SRs (13 Cochrane) \\
\hline
\end{tabular}

Equity definition

Stillbirth rates are higher in LMIC compared to HIC, and these disparities apply within countries since economically deprived communities have higher stillbirth rates due to disparities in risk factors and inequalities in access and quality of care. $98 \%$ of stillbirths occur in LMIC

Is judgment of equity made, if so, how?

Stillbirths are preventable, and occur in higher rates in economically deprived both within and between countries 
Haws 2009 (Continued)

\begin{tabular}{ll}
$\begin{array}{l}\text { Rationale for assessing PROGRESS-Plus } \\
\text { dimension }\end{array}$ & $\begin{array}{l}\text { In order to increase global attention to stillbirths, it is important to assemble a convincing } \\
\text { evidence base for risk factors for stillbirths and for preventive interventions, particularly } \\
\text { in low-income countries } \\
\text { where most stillbirths occur. }\end{array}$ \\
\hline Notes & \\
\hline
\end{tabular}

\section{Risk of bias}

\begin{tabular}{|c|c|c|}
\hline Item & Authors' judgement & Description \\
\hline Selection bias? & Yes & $\begin{array}{l}\text { Selected according to specified inclusion } \\
\text { criteria that it report rate of still births } \\
\text { and was a biologically plausible interven- } \\
\text { tion identified by systematic search of mul- } \\
\text { tiple databases }\end{array}$ \\
\hline Detection bias? & Unclear & $\begin{array}{l}\text { Method of extracting data and who per- } \\
\text { formed data extraction was not provided }\end{array}$ \\
\hline
\end{tabular}

\section{Jepson 2010}

\begin{tabular}{|c|c|}
\hline Methods & $\begin{array}{l}\text { Review of reviews to assess effectiveness of behavioural change interventions on health } \\
\text { behaviours and health inequalities. "Subsidiary aim of the review was explore, where } \\
\text { possible, the evidence of impact of interventions on health inequalities" }\end{array}$ \\
\hline Data & $\begin{array}{l}\text { "health inequalities", no specification of how health inequalities was defined, though } \\
\text { ethnicity, sex, age and socioeconomic status were described in the results }\end{array}$ \\
\hline Comparisons & Gap \\
\hline Outcomes & 103 systematic reviews \\
\hline Equity definition & $\begin{array}{l}\text { Equity not defined. Differences in behaviours, access, recruitment, effectiveness across } \\
\text { socioeconomic status, age, gender, occupations, race/ethnicity were described as impor- } \\
\text { tant for understanding how interventions work in different settings and contexts }\end{array}$ \\
\hline Is judgment of equity made, if so, how? & No judgment of equity described. \\
\hline $\begin{array}{l}\text { Rationale for assessing PROGRESS-Plus } \\
\text { dimension }\end{array}$ & $\begin{array}{l}\text { Need to take into account the socio-economic and cultural contexts within which people } \\
\text { are located. Also, illness clusters within lower socio-economic groups thus those con- } \\
\text { ducting systematic reviews (as well as those designing interventions) need to make health } \\
\text { inequalities a central concern }\end{array}$ \\
\hline Notes & \\
\hline
\end{tabular}

Risk of bias

How effects on health equity are assessed in systematic reviews of interventions (Review) 
Jepson 2010 (Continued)

\begin{tabular}{l|l|l}
\hline Item & Authors' judgement & Description \\
\hline Selection bias? & Yes & $\begin{array}{l}\text { Systematic searches in electronic databases, } \\
\text { screened using pre-specified inclusion cri- } \\
\text { teria, independently screened by 2 review- } \\
\text { ers }\end{array}$ \\
\hline Detection bias? & Unclear & $\begin{array}{l}\text { Data extraction was by one of } 4 \text { reviewers, } \\
\text { and a sample was checked by another re- } \\
\text { viewer }\end{array}$ \\
\hline
\end{tabular}

Johnson 2003

Methods

\begin{tabular}{ll}
\hline Data & Gen \\
\hline Comparisons & Gap \\
\hline
\end{tabular}

Outcomes

\section{Cochrane SRs}

Equity definition

Is judgment of equity made, if so, how?

Gender-based analysis if: 1) analysis of results broken down by gender; or 2) textual comparisons of results in men and women

Rationale for assessing PROGRESS-Plus dimension

Imperative that the practice of medicine be based on high-quality evidence, including evidence on women. CVD is number one killer of women, yet clinical trials performed predominantly in men

Notes

\section{Risk of bias}

\begin{tabular}{l|ll}
\hline Item & Authors' judgement & Description \\
\hline Selection bias? & Yes & $\begin{array}{l}\text { Included all completed systematic reviews } \\
\text { in Cochrane Heart group, Hypertension } \\
\text { group, peripheral vascular diseases group. }\end{array}$ \\
\hline Detection bias? & Unclear & $\begin{array}{l}\text { Method of extraction not described but de- } \\
\text { tails of data to be extracted were provided }\end{array}$ \\
\hline
\end{tabular}


Jones 2003

Methods

Aimed to identify how many child lives could be saved if known effective interventions were available. Collected evidence on interventions from systematic reviews or randomized trials. Assessed relevance to preventing child deaths in LMIC (level 1, 2 or 3), then modeled number of lives that could be saved

\begin{tabular}{ll}
\hline Data & LMIC \\
\hline Comparisons & Targeted \\
\hline
\end{tabular}

Outcomes

10 systematic reviews (plus other study designs for some interventions)

Equity definition

"More than 10 million children dying every year, almost all in low-income countries or poor

areas of middle-income countries. $190 \%$ of these deaths occurred in just 42 countries, most from one of a short list of causes: diarrhoea, pneumonia, measles, malaria, HIV/ AIDS, and the underlying cause of undernutrition for deaths among children younger than 5 years, and asphyxia, preterm delivery, sepsis, and tetanus for deaths among neonates"

Is judgment of equity made, if so, how? No description of equity judgment.

Rationale for assessing PROGRESS-Plus Child deaths in LMIC are preventable with known effective interventions dimension

Notes

\section{Risk of bias}

\begin{tabular}{|c|c|c|}
\hline Item & Authors' judgement & Description \\
\hline Selection bias? & Unclear & $\begin{array}{l}\text { Searches for systematic reviews in Medline } \\
\text { and Popline, search terms not provided. } \\
\text { Screening and selection methods were not } \\
\text { described }\end{array}$ \\
\hline Detection bias? & Unclear & Methods of data extraction not described \\
\hline
\end{tabular}

Lewin 2008

Methods

To summarize evidence from systematic reviews that have the potential to improve delivery of cost-effective interventions in primary health care in LMIC

\begin{tabular}{ll}
\hline Data & LMIC \\
\hline Comparisons & Targeted \\
\hline Outcomes & 20 Systematic reviews \\
\hline Equity definition & Health equity not defined, mention equitable distribution of health services \\
\hline
\end{tabular}

How effects on health equity are assessed in systematic reviews of interventions (Review)

Copyright (c) 2010 The Cochrane Collaboration. Published by John Wiley \& Sons, Ltd. 


\section{Lewin 2008 (Continued)}

Is judgment of equity made, if so, how? Inadequate delivery of cost-effective interventions is both unfair and avoidable

Rationale for assessing PROGRESS-Plus To reach Alma Ata goal of health for all, need to assess which health systems interventions dimension are applicable and relevant in LMIC

Notes

\section{Risk of bias}

\begin{tabular}{lll}
\hline Item & Authors' judgement & Description \\
\hline Selection bias? & Yes & $\begin{array}{l}\text { systematic search with prespecified inclu- } \\
\text { sion criteria, }\end{array}$ \\
\hline Detection bias? & Yes & $\begin{array}{l}\text { 2 independent reviewers screened for inclu- } \\
\text { sion and extracted data and assessed quality } \\
\text { using forms }\end{array}$ \\
\hline
\end{tabular}

Main 2008

Methods

To review effectiveness of population-level tobacco control interventions to reduce social inequalities

\begin{tabular}{ll}
\hline Data & SES \\
\hline Comparisons & Gap \\
\hline Outcomes & 19 systematic reviews \\
\hline Equity definition & Authors mention applying an equity lens \\
\hline
\end{tabular}

Is judgment of equity made, if so, how?

equity lens to assess whether systematic reviews can be used to answer questions about reducing health inequalities across SES, ethnicity education

Rationale for assessing PROGRESS-Plus dimension

Reducing social inequalities in smoking and its health consequences is a public health priority

Notes

\section{Risk of bias}

\begin{tabular}{lll}
\hline Item & Authors' judgement & Description \\
\hline Selection bias? & Yes & $\begin{array}{l}\text { Pre-defined inclusion criteria to identify } \\
\text { all SRs with details on sociodemographic } \\
\text { characteristics of participants }\end{array}$
\end{tabular}


Main 2008 (Continued)

Detection bias?

Yes

2 independent reviewers screened abstracts, extracted data and assessed quality

Menezes 2009

Methods

Systematic review of the evidence for 16 antenatal interventions with the potential to prevent stillbirths. We searched a range of sources including PubMed and the Cochrane Library. For interventions with prior Cochrane reviews, we conducted additional metaanalyses including eligible newer randomised controlled trials following the Cochrane protocol. We focused on interventions deliverable at the community level in low-/middleincome countries, where the burden of stillbirths is greatest

\begin{tabular}{ll}
\hline Data & LMIC \\
\hline Comparisons & Targeted \\
\hline Outcomes & 31 SRs $[25$ Cochrane reviews, 6 non-Cochrane SRs] \\
\hline Equity definition & $\begin{array}{l}\text { Stillbirth rates are higher in LMIC compared to HIC, and these disparities apply within } \\
\text { countries since economically deprived communities have higher stillbirth rates due to } \\
\text { disparities in risk factors and inequalities in access and quality of care. } 98 \% \text { of stillbirths } \\
\text { occur in LMIC }\end{array}$
\end{tabular}

Is judgment of equity made, if so, how?

Potentially preventable or treatable by treating infections and maternal conditions such as diabetes

Rationale for assessing PROGRESS-Plus Interventions targeting risk factors may reduce stillbirths, especially in LMIC dimension

Notes

\section{Risk of bias}

\begin{tabular}{l|l|l}
\hline Item & Authors' judgement & Description \\
\hline Selection bias? & Yes & $\begin{array}{l}\text { Selected according to specified inclusion } \\
\text { criteria that it report rate of still births } \\
\text { and was a biologically plausible interven- } \\
\text { tion identified by systematic search of mul- } \\
\text { tiple databases }\end{array}$ \\
\hline Detection bias? & Unclear & $\begin{array}{l}\text { Method of extracting data and who per- } \\
\text { formed data extraction was not provided }\end{array}$ \\
\hline
\end{tabular}


Morrison 2004

\begin{tabular}{|c|c|c|}
\hline Methods & \multicolumn{2}{|c|}{$\begin{array}{l}\text { To compile quantitative reviews of studies of adherence; to critique this literature and } \\
\text { summarize current knowledge of adherence }\end{array}$} \\
\hline Data & \multicolumn{2}{|c|}{ Gender/sex, SES and age } \\
\hline Comparisons & \multicolumn{2}{|l|}{ Gradient } \\
\hline Outcomes & \multicolumn{2}{|c|}{12 SRs, MAs or quantitative overviews } \\
\hline Equity definition & \multicolumn{2}{|l|}{ not defined } \\
\hline Is judgment of equity made, if so, how? & \multicolumn{2}{|l|}{ not done } \\
\hline $\begin{array}{l}\text { Rationale for assessing PROGRESS-Plus } \\
\text { dimension }\end{array}$ & \multicolumn{2}{|c|}{$\begin{array}{l}\text { SES, gender and age assessed as potential effect modifiers for interventions aimed at } \\
\text { increasing adherence }\end{array}$} \\
\hline \multicolumn{3}{|l|}{ Notes } \\
\hline \multicolumn{3}{|l|}{ Risk of bias } \\
\hline Item & Authors' judgemen & Description \\
\hline Selection bias? & Yes & $\begin{array}{l}\text { Any SR, MA or quantitative overview that } \\
\text { assessed adherence with prescribed medi- } \\
\text { cations; aimed at patients; more than } 1 \text { in- } \\
\text { cluded study }\end{array}$ \\
\hline Detection bias? & Unclear & Data extraction not described \\
\hline
\end{tabular}

Nasser 2007

\begin{tabular}{l|l}
\hline Methods & $\begin{array}{l}\text { To identify Cochrane reviews that are relevant to developing countries; and to determine } \\
\text { how they tackled the developing country setting }\end{array}$ \\
\hline Data & Place of residence, SES, LMIC \\
\hline Comparisons & Gap \\
\hline Outcomes & 420 Cochrane SRs \\
\hline Equity definition & Not defined nor discussed \\
\hline $\begin{array}{l}\text { Is judgment of equity made, if so, how? } \\
\text { Rationale for assessing PROGRESS-Plus }\end{array}$ & $\begin{array}{l}\text { Nifferent prevalence in LMIC; cost-effectiveness more important in LMIC, challenges } \\
\text { in implementation may be different in LMIC than HIC }\end{array}$ \\
\hline
\end{tabular}

Notes

How effects on health equity are assessed in systematic reviews of interventions (Review)

Copyright $\odot 2010$ The Cochrane Collaboration. Published by John Wiley \& Sons, Ltd. 
Nasser 2007 (Continued)

\section{Risk of bias}

\begin{tabular}{lll}
\hline Item & Authors' judgement & Description \\
\hline Selection bias? & Yes & $\begin{array}{l}\text { all SRs that mentioned LMIC in title, ab- } \\
\text { stract or text were included }\end{array}$ \\
\hline Detection bias? & No & methods for data extraction not described \\
\hline
\end{tabular}

Odierna 2009

\begin{tabular}{|c|c|c|}
\hline Methods & \multicolumn{2}{|c|}{$\begin{array}{l}\text { To assess racial/ethnic, gender, and socioeconomic status (SES) concordance between } \\
\text { Medicaid populations and studies synthesized in Drug Effectiveness Review Project } \\
\text { (DERP) systematic reviews }\end{array}$} \\
\hline Data & \multicolumn{2}{|l|}{ SES, race/ethnicity } \\
\hline Comparisons & \multicolumn{2}{|l|}{ Gap } \\
\hline Outcomes & \multicolumn{2}{|l|}{32 systematic reviews } \\
\hline Equity definition & \multicolumn{2}{|c|}{$\begin{array}{l}\text { Health equity defined as eliminating avoidable inequalities, particularly those that result } \\
\text { from injustice or social exclusion }\end{array}$} \\
\hline Is judgment of equity made, if so, how? & \multicolumn{2}{|c|}{$\begin{array}{l}\text { Health equity requires improving health outcomes for all sectors of the population, not } \\
\text { benefitting only the advantaged }\end{array}$} \\
\hline $\begin{array}{l}\text { Rationale for assessing PROGRESS-Plus } \\
\text { dimension }\end{array}$ & \multicolumn{2}{|c|}{$\begin{array}{l}\text { Health policies need to be evaluated to ensure that they are not unintentionally increasing } \\
\text { health inequalities }\end{array}$} \\
\hline \multicolumn{3}{|l|}{ Notes } \\
\hline \multicolumn{3}{|l|}{ Risk of bias } \\
\hline Item & Authors' judgement & Description \\
\hline Selection bias? & Yes & $\begin{array}{l}\text { All drug effectiveness reviews from 2004- } \\
2007 \text { were included }\end{array}$ \\
\hline Detection bias? & Yes & $\begin{array}{l}\text { One reviewer extracted data, and this was } \\
\text { verified by a second reviewer }\end{array}$ \\
\hline
\end{tabular}


Ogilvie 2004

\begin{tabular}{|c|c|c|}
\hline Methods & \multicolumn{2}{|c|}{$\begin{array}{l}\text { To assess the potential contribution of evidence from existing systematic reviews of } \\
\text { effectiveness to answering the question: what works in reducing social inequalities in } \\
\text { smoking? }\end{array}$} \\
\hline Data & \multicolumn{2}{|c|}{$\begin{array}{l}\text { "any socio-demographic variable“, not further defined, but later mentions age, sex and } \\
\text { SES }\end{array}$} \\
\hline Comparisons & \multicolumn{2}{|l|}{ Gap } \\
\hline Outcomes & \multicolumn{2}{|l|}{6 Cochrane SRs } \\
\hline Equity definition & \multicolumn{2}{|c|}{$\begin{array}{l}\text { Not defined, review intends to assess "social distribution of intervention effects", "social } \\
\text { inclusiveness or targeting of interventions }\end{array}$} \\
\hline Is judgment of equity made, if so, how? & \multicolumn{2}{|c|}{ No judgment on fairness, all inequalities across social dimensions are assessed } \\
\hline $\begin{array}{l}\text { Rationale for assessing PROGRESS-Plus } \\
\text { dimension }\end{array}$ & \multicolumn{2}{|c|}{$\begin{array}{l}\text { Reducing social inequalities in a political priority- is evidence available that tobacco } \\
\text { control policies will help achieve this? }\end{array}$} \\
\hline \multicolumn{3}{|l|}{ Notes } \\
\hline \multicolumn{3}{|l|}{ Risk of bias } \\
\hline Item & Authors' judgement & Description \\
\hline Selection bias? & Yes & $\begin{array}{l}\text { All completed reviews of the effectiveness } \\
\text { of community-base tobacco control inter- } \\
\text { ventions }\end{array}$ \\
\hline Detection bias? & Unclear & $\begin{array}{l}\text { Data extraction methods not described but } \\
\text { data to be collected were described }\end{array}$ \\
\hline
\end{tabular}

Shea 2009

\begin{tabular}{l|l}
\hline Methods & Overview of 4 SRs on increasing demand for childhood vaccinations in LMIC \\
\hline Data & LMIC \\
\hline Comparisons & Targeted \\
\hline Outcomes & 4 systematic reviews \\
\hline Equity definition & Not defined. \\
\hline \begin{tabular}{l} 
Is judgment of equity made, if so, how? \\
\hline $\begin{array}{l}\text { Rationale for assessing PROGRESS-Plus } \\
\text { dimension }\end{array}$
\end{tabular} & Importance of problem of how to increase childhood vaccination in developing countries \\
\hline
\end{tabular}

How effects on health equity are assessed in systematic reviews of interventions (Review) 
Shea 2009 (Continued)

\begin{tabular}{|c|c|c|}
\hline Notes & & \\
\hline \multicolumn{3}{|l|}{ Risk of bias } \\
\hline Item & Authors' judgement & Description \\
\hline Selection bias? & Yes & $\begin{array}{l}\text { Systematic search, with inclusion criteria, a } \\
\text { priori protocol, screening by } 2 \text { reviewers }\end{array}$ \\
\hline Detection bias? & Unclear & Method of data extraction not reported \\
\hline
\end{tabular}

\section{Sherr 2009}

Methods

Conducted gender analysis on 6 SRs related to children and HIV: 1) Hiv treatment resistance, 2) adherence to treatment, 3) HIV and schooling, 4) HIV and nutrition, 5) HIV and cognitive development, 6) HIV and bereavement

\begin{tabular}{ll}
\hline Data & Gender/sex \\
\hline Comparisons & Targeted and gap \\
\hline Outcomes & 6 systematic reviews (2 Cochrane and 4 were conducted as part of this study) \\
\hline Equity definition & $\begin{array}{l}\text { Social and cultural aspects of gender which disadvanatge or disempower subgroups, } \\
\text { gender discrimination }\end{array}$
\end{tabular}

Is judgment of equity made, if so, how?

gender affects the biological susceptibility to IV/AIDS as well as the social susceptibility through gender roles, gender differences and gender responses, including gender discrimination. Social and cultural constructs of gender disadvantage or disempower subgroups, violence, sexual attitudes

Rationale for assessing PROGRESS-Plus gender affects the biological susceptibility to IV/AIDS as well as the social susceptibility dimension through gender roles, gender differences and gender responses, including gender discrimination. Social and cultural constructs of gender disadvantage or disempower subgroups, violence, sexual attitudes

Notes

Risk of bias

\begin{tabular}{|c|c|c|}
\hline Item & Authors' judgement & Description \\
\hline Selection bias? & Unclear & $\begin{array}{l}\text { For two topics, SRs existed, for } 4 \text { topics, } \\
\text { they conducted a SR. A priori protocol, } \\
\text { double extraction and screening were not } \\
\text { mentioned }\end{array}$ \\
\hline
\end{tabular}


Sherr 2009 (Continued)

\begin{tabular}{|c|c|c|}
\hline Detection bias? & Unclear & $\begin{array}{l}\text { Methods for extracting data were not de- } \\
\text { scribed. Eg no description of who extracted } \\
\text { the data or whether they used a pre-deter- } \\
\text { mined extraction form }\end{array}$ \\
\hline
\end{tabular}

\section{Stewart 2006}

\begin{tabular}{|c|c|c|}
\hline Methods & \multicolumn{2}{|c|}{$\begin{array}{l}\text { What factors help or hinder the process of transition to adulthood for youth with dis- } \\
\text { abilities? What service delivery methods have been used? }\end{array}$} \\
\hline Data & \multicolumn{2}{|c|}{ Plus- youth with disabilities } \\
\hline Comparisons & \multicolumn{2}{|l|}{ Targeted } \\
\hline Outcomes & \multicolumn{2}{|l|}{5 systematic reviews } \\
\hline Equity definition & \multicolumn{2}{|l|}{ Equity not defined } \\
\hline Is judgment of equity made, if so, how? & \multicolumn{2}{|c|}{ Authors describe worse outcomes in youth with disabilities than their peers } \\
\hline $\begin{array}{l}\text { Rationale for assessing PROGRESS-Plus } \\
\text { dimension }\end{array}$ & \multicolumn{2}{|c|}{$\begin{array}{l}\text { Youth with disabilities do not have same outcomes as peers for health, achievement and } \\
\text { employment }\end{array}$} \\
\hline \multicolumn{3}{|l|}{ Notes } \\
\hline \multicolumn{3}{|l|}{ Risk of bias } \\
\hline Item & Authors' judgement & Description \\
\hline Selection bias? & Yes & $\begin{array}{l}\text { Pre-specified inclusion criteria to identify } \\
\text { systematic reviews }\end{array}$ \\
\hline Detection bias? & Yes & $\begin{array}{l}\text { Risk of bias: extracted details using Critical } \\
\text { Appraisal Skills Program }\end{array}$ \\
\hline
\end{tabular}

\section{Tsikata 2003}

\begin{tabular}{|c|c|}
\hline Methods & $\begin{array}{l}\text { To determine whether Cochrane reviews report and analyze the data needed to assess the } \\
\text { effectiveness of interventions at reducing health inequities }\end{array}$ \\
\hline Data & PROGRESS-Plus \\
\hline Comparisons & Gap \\
\hline Outcomes & 95 Cochrane SRs \\
\hline Equity definition & Health inequities defined as avoidable and unfair inequalities in health, across SES \\
\hline
\end{tabular}


Tsikata 2003 (Continued)
Is judgment of equity made, if so, how?
All inequalities across PROGRESS were assessed

Rationale for assessing PROGRESS-Plus Need for evidence on what works to reduce inequalities across socioeconomic strata dimension

\section{Notes}

\section{Risk of bias}

\begin{tabular}{|c|c|c|}
\hline Item & Authors' judgement & Description \\
\hline Selection bias? & Yes & $\begin{array}{l}\text { Random sample of } 10 \% \text { of systematic re- } \\
\text { views published between issue } 1,2000 \text { to is- } \\
\text { sue } 2,2003 \text { in the Cochrane Library; strati- } \\
\text { fied by review group ( } n=42 ; 7 \text { Cochrane re- } \\
\text { view groups excluded because }<5 \text { reviews) }\end{array}$ \\
\hline Detection bias? & Yes & $\begin{array}{l}\text { Data extraction was done by } 2 \text { reviewers, } \\
\text { using a pre-tested form; discrepancies re- } \\
\text { solved by discussion }\end{array}$ \\
\hline
\end{tabular}

\section{Tugwell 2008}

\begin{tabular}{l|l}
\hline Methods & To apply the "equity lens" to Cochrane reviews of rheumatoid arthritis \\
\hline Data & PROGRESS \\
\hline Comparisons & Gap \\
\hline Outcomes & 14 Cochrane SRs \\
\hline Equity definition & Health equity defined as: 1 ) effective in people who are disadvantaged or; \\
\hline Is judgment of equity made, if so, how? & fairness and avoidability referenced, but not judged by authors \\
\hline $\begin{array}{l}\text { Rationale for assessing PROGRESS-Plus } \\
\text { dimension }\end{array}$ & Need for evidence on what works to reduce inequalities across socioeconomic strata \\
\hline \begin{tabular}{l} 
Notes \\
\hline
\end{tabular}
\end{tabular}

\section{Risk of bias}

\begin{tabular}{lll}
\hline Item & Authors' judgement & Description \\
\hline Selection bias? & Yes & $\begin{array}{l}\text { All systematic reviews of the musculoskele- } \\
\text { tal review group published since Issue 1, } \\
2003\end{array}$
\end{tabular}


Tugwell 2008 (Continued)

\begin{tabular}{|c|c|c|}
\hline Detection bias? & Yes & $\begin{array}{l}\text { Double extraction by } 2 \text { reviewers with pre- } \\
\text { tested form }\end{array}$ \\
\hline
\end{tabular}

Vergidis 2009

\begin{tabular}{|c|c|c|}
\hline Methods & \multicolumn{2}{|c|}{$\begin{array}{l}\text { Identified } 18 \text { meta-analyses of interventions specifically focused at populations that are } \\
\text { at high risk for high risk behaviour: minority populations (Latinos, African/Americans) } \\
\text {, men who have sex with men, injection drug users and people living with HIV }\end{array}$} \\
\hline Data & \multicolumn{2}{|c|}{$\begin{array}{l}\text { Race/ethnicity [minority populations], "Plus": [men who have sex with men, injection } \\
\text { drug users, people living with HIV] }\end{array}$} \\
\hline Comparisons & \multicolumn{2}{|l|}{ Targeted } \\
\hline Outcomes & \multicolumn{2}{|l|}{18 systematic reviews } \\
\hline Equity definition & \multicolumn{2}{|l|}{ Not defined. } \\
\hline Is judgment of equity made, if so, how? & \multicolumn{2}{|l|}{ No judgment of equity } \\
\hline $\begin{array}{l}\text { Rationale for assessing PROGRESS-Plus } \\
\text { dimension }\end{array}$ & \multicolumn{2}{|c|}{ Behavioural interventions are aimed at specific populations } \\
\hline \multicolumn{3}{|l|}{ Notes } \\
\hline \multicolumn{3}{|l|}{ Risk of bias } \\
\hline Item & Authors' judgement & Description \\
\hline Selection bias? & No & $\begin{array}{l}\text { Method of identifying meta-analyses was } \\
\text { not reported. }\end{array}$ \\
\hline Detection bias? & No & $\begin{array}{l}\text { Methods for data extraction were not re- } \\
\text { ported }\end{array}$ \\
\hline
\end{tabular}

\section{Viswanathan 2008}

\begin{tabular}{l|l} 
Methods & $\begin{array}{l}\text { To summarize maternal health research priorities, map these priorities to existing reviews, } \\
\text { identify gaps that can be addressed with systematic reviews, including racial disparities }\end{array}$ \\
\hline Data & Race, ethnicity \\
\hline Comparisons & Gap \\
\hline Outcomes & 64 systematic reviews
\end{tabular}


Viswanathan 2008 (Continued)

\begin{tabular}{|c|c|c|}
\hline Equity definition & \multicolumn{2}{|l|}{ Equity not defined. } \\
\hline Is judgment of equity made, if so, how? & \multicolumn{2}{|c|}{ Disparities in health outcomes remain after adjusting for medical risk } \\
\hline $\begin{array}{l}\text { Rationale for assessing PROGRESS-Plus } \\
\text { dimension }\end{array}$ & \multicolumn{2}{|c|}{$\begin{array}{l}\text { Persistent disparity in health outcomes by race suggests a role for further research on } \\
\text { interventions that narrow the gap }\end{array}$} \\
\hline \multicolumn{3}{|l|}{ Notes } \\
\hline \multicolumn{3}{|l|}{ Risk of bias } \\
\hline Item & Authors' judgement & Description \\
\hline Selection bias? & Yes & $\begin{array}{l}\text { Search of medline using MESH delivery, } \\
\text { obstetric, systematic reviews, relevant to } \\
\mathrm{MCH}\end{array}$ \\
\hline Detection bias? & Unclear & $\begin{array}{l}\text { Authors state "each study was reviewed to } \\
\text { establish nature of intervention, primary } \\
\text { outcome and subanalysis of racial dispari- } \\
\text { ties }\end{array}$ \\
\hline
\end{tabular}

Yakoob 2009

Methods

Systematic overview of systematic reviews, primary studies on covers 12 different interventions relating to behavioural and socially mediated risk factors, including exposures to harmful practices and substances, antenatal care utilisation and quality, and maternal nutrition before and during pregnancy

\begin{tabular}{ll}
\hline Data & LMIC \\
\hline Comparisons & Targeted \\
\hline Outcomes & 14 Cochrane, 2 non-Cochrane $=16$ SRs \\
\hline
\end{tabular}

Equity definition

from overview paper $\{9074\}$, stillbirth rates are higher in LMIC compared to HIC, and these disparities apply within countries since economically deprived communities have higher stillbirth rates due to disparities in risk factors and inequalities in access and quality of care. $98 \%$ of stillbirths occur in LMIC

Is judgment of equity made, if so, how?

Many stillbirths are preventable by access to antenatal care and obstetric care, and by reducing risk factors

Rationale for assessing PROGRESS-Plus dimension

In order to increase global attention to stillbirths, it is important to assemble a convincing evidence base for risk factors for stillbirths and for preventive interventions, particularly in low-income countries where most stillbirths occur. 
Yakoob 2009 (Continued)

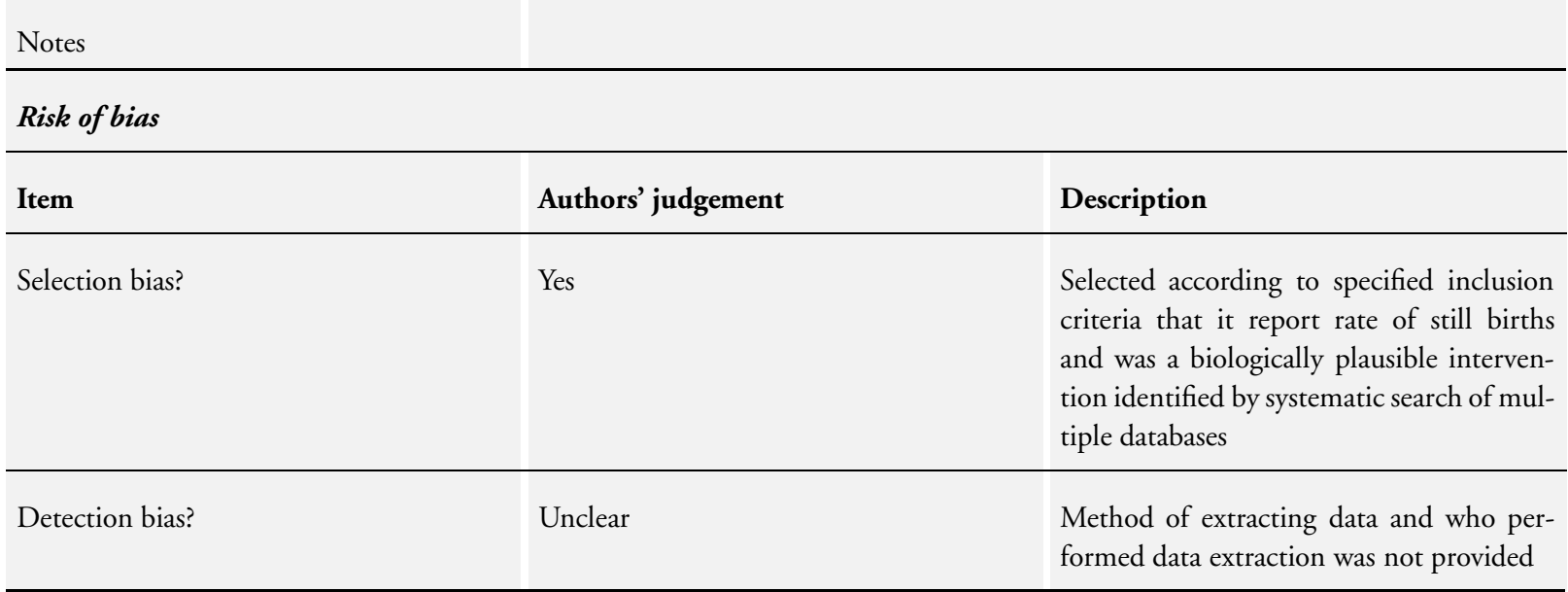

PROGRESS-Plus: Place of residence (urban/rural), Race/ethnicity, Occupation, Gender, Religion, Education, Socioeconomic status and Social Capital; "Plus" captures other factors which are associated with decreased opportunity for good health such as disability, sexual preference, disease status or resource-poor settings; SR: Systematic Review; LMIC: Low and Middle Income Countries; HIC: High income countries; MA: meta-analysis; SES: socioeconomic status

\section{Characteristics of excluded studies [ordered by study ID]}

\begin{tabular}{|c|c|}
\hline Study & Reason for exclusion \\
\hline Ahmad 2010 & $\begin{array}{l}\text { Assessed reporting of sex, age and race in a cohort of } 98 \text { SRs on tobacco control and HIV. No assessment } \\
\text { of differences in health outcomes across these characteristics }\end{array}$ \\
\hline AHRQ 2010 & $\begin{array}{l}\text { No assessment of effects on health equity or health inequalities. A cohort of systematic reviews was eval- } \\
\text { uated to assess how clinical heterogeneity was assessed, including whether population characteristics are } \\
\text { prespecified for subgroup analyses }\end{array}$ \\
\hline Barlow 2004 & $\begin{array}{l}\text { No focus on health equity. Assessed effects of interventions for children with chronic disease using SRs but } \\
\text { made no judgment that these children were disadvantaged or that these interventions could affect health } \\
\text { inequalities or health inequities }\end{array}$ \\
\hline Craig 2003 & No focus on health equity. Assessment of effects of treatments for sexual offenders from SRs \\
\hline Espinosa-Aguilar 2007 & $\begin{array}{l}\text { No focus on health equity. } 8 \text { SRs were included on effects of interventions in the elderly, with no focus on } \\
\text { equity, inequalities or disadvantage }\end{array}$ \\
\hline Gaes 1999 & No focus on health equity. Assesses effectiveness of correctional rehabilitation using SRs \\
\hline Gulmezoglu 1997 & No focus on health equity. Assessed effects of interventions to prevent impaired fetal growth \\
\hline
\end{tabular}


(Continued)

Thomas 2008

Not a cohort of systematic reviews. This is a single systematic review of tobacco control interventions

Characteristics of ongoing studies [ordered by study ID]

Panteli 2009

Trial name or title Equity and Health technology assessment

Methods $\quad$ systematic review of equity considerations in HTA

Data HTA reports

Comparisons $\quad$ Equity issues were classified according to HTA core domains

Outcomes

Starting date

Contact information dpanteli@mailbox.tu-berlin.de

Notes 


\section{DATA ANDANALYSES}

This review has no analyses.

\section{ADDITIONAL TABLES}

Table 1. Selected methods of assessing effects on health inequalities

\begin{tabular}{|c|c|}
\hline Method & Calculation \\
\hline Targeted approach & $\begin{array}{l}\text { Evaluation of effect size in the disadvantaged population only (e.g. Cochrane Review on com- } \\
\text { munity animal health services for improving household wealth and health status of low income } \\
\text { farmers by Curran 2006). }\end{array}$ \\
\hline Relative difference (gap approach) & (advantaged - disadvantaged)/advantaged \\
\hline Absolute difference (gap approach) & advantaged - disadvantaged \\
\hline Gradient-approach regression & Regression-based index of relative effect across incremental categories of disadvantage \\
\hline Gradient-concentration index & $\begin{array}{l}\text { Twice the area between the concentration curve and the line of equality ( } 45 \text { degrees line), } \\
\text { defined with reference to the concentration curve, which graphs health status on the y-axis } \\
\text { against categories of disadvantage on the x-axis (World Bank). }\end{array}$ \\
\hline Gradient or gap-benefit incidence & $\begin{array}{l}\text { Computes the distribution of public expenditure across different PROGRESS-Plus groups } \\
\text { according to actual utilization of services }\end{array}$ \\
\hline Gradient approach - Gini index & $\begin{array}{l}\text { Measure of inequality of income distribution, defined as the area between the line of equality } \\
\text { and the Lorenz curve, with categories of PROGRESS on the x-axis and percentage of total } \\
\text { income on the y-axis (Gastwirth 1972). }\end{array}$ \\
\hline
\end{tabular}

Table 2. Methods used to assess whether health equity was considered in systematic reviews

\begin{tabular}{|c|c|c|c|c|}
\hline $\begin{array}{l}\text { Methods used to assess } \\
\text { health equity effects }\end{array}$ & $\begin{array}{l}\text { Which studies used this } \\
\text { method }\end{array}$ & Data availability & Advantages & Disadvantages \\
\hline $\begin{array}{l}\text { la. De- } \\
\text { scriptive- SRs mention } \\
\text { PROGRESS-Plus }\end{array}$ & $\begin{array}{l}\text { Doull 2010, Nasser } \\
\text { 2007, Lewin 2008; Sherr } \\
2009\end{array}$ & $\begin{array}{l}\text { Gender/sex (15/44 SRs) } \\
\text {, LMIC (6/20 SRs) }\end{array}$ & $\begin{array}{l}\text { Indicates whether au- } \\
\text { thors of systematic re- } \\
\text { views have considered } \\
\text { health equity }\end{array}$ & $\begin{array}{l}\text { Does not assess effects on } \\
\text { health equity or health } \\
\text { inequalities }\end{array}$ \\
\hline $\begin{array}{l}\text { 1b. Descriptive- SRs de- } \\
\text { scribe population across } \\
\text { PROGRESS-Plus factor } \\
\text { (s) }\end{array}$ & $\begin{array}{l}\text { Nasser 2007, Doull } \\
\text { 2010, Tugwell 2008, } \\
\text { Ogilvie 2004, Tsikata } \\
\text { 2003, Lewin 2008; Sherr }\end{array}$ & $\begin{array}{l}2 \text { studies did not re- } \\
\text { port data availability ( } \\
\text { Nasser 2007; Ogilvie } \\
\text { 2004); For the other }\end{array}$ & $\begin{array}{l}\text { Provides direct data on } \\
\text { whether different popu- } \\
\text { lations included in SRs }\end{array}$ & $\begin{array}{l}\text { Does not analyze influ- } \\
\text { ence of population char- } \\
\text { acteristics or setting on }\end{array}$ \\
\hline
\end{tabular}


2009; Yakoob 2009; Haws 2009; Darmstadt 2009; Bhutta 2009; Menezes 2009
3 studies, PROGRESSPlus data was available for: Place of residence (5/95 SRs); race/ethnicity (7/95 SRs); occupation (1/95 SRs); gender/ sex (90/153 SRs); religion (1/95 SRs); education (0/95 SRs); SES (4/ 95 SRs); social capital (0/ 95 SRs), LMIC (13/58 SRs reported $>1$ study in LMIC) 1c. Descriptive- SR de- Nasser 2007, Ogilvie scribes if intervention is 2004, Tsikata 2003; given only to disadvan- Main 2008, Adamek taged populations across 2008, Stewart 2006, PROGRESS-Plus

D’Souza 2004, Ball 2002, Browne 2004;

Tugwell 2008; Bartels 2003,

Bhutta 2008, Shea 2009, Jones 2003, Darmstadt 2005, Vergidis 2009, Bhutta 2009, Darmstadt 2009, Haws 2009, Menezes 2009, Sherr 2009, Yakoob 2009
Data not reported for 2 Assesses if interventions studies (Ogilvie 2004), (Nasser 2007); 17/114 SRs described interventions aimed at people defined by race/ethnicity, gender/sex, low SES or age (Tsikata 2003; Main 2008); seven methodology studies selected only SRs that focused on disad-

vantaged groups across PROGRESS; 100/ 217 SRs included studies conducted in LMICs

Three overviews described that some systematic reviews were conducted in LMIC, but did not report details for all SRs cific disadvantaged pop- which is useful for judging applicability

effects on health inequalities

Data available for gender in $57 \%$ of SRs, others are available in less than $25 \%$ of SRs have been tested in spe- intervention ulations

Can be misleading since SRs with no studies conducted in disadvantaged populations may still be relevant and applicable 1d. Descriptive- Outcomes of SR related to equity of access
Tsikata 2003, Nasser 2007, Althabe 2008, Lewin 2008, Bambra 2010, Chopra 2008, Jepson 2010
Equity of access mea- Provides data on access sured in $18 / 173$ SRs. to health care, a determiData not reported by nant of health inequalione study (Nasser 2007) ties . One overview reported that no SRs had details about equity of access ( Jepson 2010)
Data on access to care does not measure effects on health inequalities

Measuring access to health care is dependent on the question and availability of data depends on selection criteria of methodology review 
1e. Descriptive- describe if SRs conduct or plan subgroup analyses across PROGRESS-Plus
Tugwell 2008; Ogilvie 2004; Johnson 2003; Tsikata Main 2008, Lewin 2008, Race/ethnicity (12/262) Odierna 2009, Bambra ; Occupation (0); Gen2010; Sherr 2009

Analy-

sis by PROGRESS-Plus subgroup in 22/198 SRs;

Place of residence; der 19/204; Religion (0) ; Occupation (0); Gen; Education (0); SES (1/ 198); 6/49 SRs assess differences across SES, gender or race

2a. Descriptive- asses if primary studies describe population across PROGRESS-Plus

\section{Tugwell 2008; Tsikata} 2003, Johnson 2003, Ogilvie 2004 for 1 SR; Sherr 2009, Vergidis 2009, Bhutta 2009, Darmstadt 2009, Haws 2009, Menezes 2009, Yakoob 2009
Place of residence (26/ 263), race/ethnicity (42/

263), occupation (24/ 250), gender/sex (260/ $350)$, religion (0), education (42/263), SES (25/

263), Social capital (24/ 250) 227/836 conducted in LMIC RCTs
Subgroup analysis pro- Lack of data: data availvides direct data needed able by PROGRESSto answer whether the Plus subgroups of interintervention works the est in $10 \%$ of SRs (28/ same or differently in 247 had data) populations of interest

Provides evidence on Data may not whether sufficient evi- be available stratified by dence is available from PROGRESS-Plus facprimary studies to con- tors in the primary studduct subgroup analyses ies in SRs

11 of 147 primary studies stratified by one or more PROGRESSPlus (Tugwell 2008); 96/366 assessed gender/ sex (Johnson 2003; Sherr 2009); $10 / 76$ and $5 / 14$ stratified by sex (Ogilvie 2004); 7/103 stratified by education, sex or SES (Tsikata 2003).

In Sherr 2009; SRs were classified according to whether there was positive, negative or no effect of gender [32/108 RCTs analyzed effects by gender (sic)]

In Jepson 2010, 2/103 SRs were described as assessing "effect modifiers" such as sex, age, ethnicity and socioeconomic status
Identifies whether sub- Time-consuming to asgroup analyses sess all primary studies of across PROGRESS-Plus included SRs are available in primary studies and the direction Does not rule out the and magnitude of effects possibility of spurious in different populations statistical significance 
3a. Analytic: association Morrison 2004, Sherr 2009
Age in $8 / 12$ SRs; Sex in $7 / 12$ SRs; SES in $5 / 12$ SRs.

In one overview, gender analysis was conducted and the effect of gender was assessed as positive, negative or no effect on results (Sherr 2009)
Indicates whether Data unavailable for PROGRESS-Plus fac- $33 \%$ of SRs (4/12) tors are associated with different relative effects

Could be used to assess gradients of effect modification according to different levels of PROGRESS-Plus (e.g. poverty)

3b. Analytic: rela- None

tive comparison of effect

size in two groups using

an odds ratio

3c. Analytic: assess effects in a disadvantaged population
Adamek 2008, Stewart Identified median of 11 2006, D'Souza 2004, Ball 2002, Browne 2004; Bartels 2003, Vergidis 2009, Jepson 2010

SRs with targeted evi-

dence (range 5-23); three studies reported medium to large effect sizes of interventions targeted at depression in older adults (Adamek 2008) , youth with disabilities (D'Souza 2004) and mental health promotion in children (Browne 2004). One study reported effect sizes for specific populations: $\mathrm{mi}-$ nority populations, men who have sex with men, injection drug users and people with HIV, and reported a synthesized effect size of 1.34 (95\% confidence interval of 1. 13 to 1.64 ) (Vergidis 2009). Three studies did not report effect sizes
Directly applicable for Lack of data in some disdecisions about inter- advantaged populations ventions in these spe- limits the use of this apcific disadvantaged pop- proach for other populaulations tions and settings

Identifies evidence gaps

Low methodological quality of SRs may limit applicability

Lack of data on process of implementation 4a. Applicability: assess likely impact on disadvantaged populations using checklists for applicability and equity
Althabe 2008, Lewin 2008, Chopra 2008, Barros 2010, Darmstadt 2005, 2003, Bhutta 2009, Darmstadt 2009, Haws
8/20 SRs were considered most transferable to LMIC setting (Lewin 2008), 1 study only included SRs if they were deemed applicable in Standardized
Useful summary for policy-makers about likely relevance in LMIC settings
Does not assess the magnitude of effect in different populations

Requires content and methodological 
2009, Menezes 2009, Yakoob 2009
LMIC settings (Althabe 2008), 1 study assessed applicability to LMIC settings using the SUPPORT checklist

GRADE was used to assessed quality of evidence which includes an assessment of directness to the population of interest (LMIC in these studies) in three studies (Barros 2010, Bhutta 2008, Lewin 2008).

Two studies used criteria of biological plausibility, impact and feasibility in LMIC (see Appendix 7) (Jones 2003, Darmstadt 2005)

Five studies used the SIGN tools which assess directness, and also considered the feasibility and potential impact of these interventions in resource poor settings (Bhutta 2009, Darmstadt 2009, Haws 2009, Menezes 2009, Yakoob 2009) format makes judgments explicit and transparent

Does not require replication of studies in different populations and settings

Not subject to statistical power issues of subgroup analyses expertise to make equity and applicability judgments

Low availability of data to make judgments ( Althabe 2008), (Lewin 2008), (Chopra 2008)

SES: Socioeconomic status; PROGRESS: PROGRESS: Place of residence (urban/rural), Race/ethnicity, Occupation, Gender, Religion,

Education, Socioeconomic status and Social Capital

Table 3. Subgroup analyses: assessment against credibility criteria

\begin{tabular}{|c|c|c|c|c|c|c|c|c|c|c|c|}
\hline & $\begin{array}{l}\text { Johnson } \\
2003\end{array}$ & $\begin{array}{l}\text { Tsikata } \\
2003\end{array}$ & $\begin{array}{l}\text { Ogilvie } \\
2004\end{array}$ & $\begin{array}{l}\text { Odierna } \\
2009\end{array}$ & $\begin{array}{l}\text { Lewin } \\
2008\end{array}$ & $\begin{array}{l}\text { Tugwell } \\
2008\end{array}$ & $\begin{array}{l}\text { Viswanath } \\
2008\end{array}$ & $\begin{array}{l}\text { Main } \\
2008\end{array}$ & $\begin{array}{l}\text { Bambra } \\
2010\end{array}$ & $\begin{array}{l}\text { Sherr } \\
2009\end{array}$ & $\begin{array}{l}\text { Jepson } \\
2010\end{array}$ \\
\hline $\begin{array}{l}\text { Clini- } \\
\text { cally im- } \\
\text { por- } \\
\text { tant dif- } \\
\text { ference }\end{array}$ & $\begin{array}{l}\text { Not de- } \\
\text { scribed }\end{array}$ & $\begin{array}{l}\text { Not de- } \\
\text { scribed }\end{array}$ & $\begin{array}{l}\text { Not de- } \\
\text { scribed }\end{array}$ & $\begin{array}{l}\text { Not de- } \\
\text { scribed }\end{array}$ & $\begin{array}{l}\text { Yes, dif- } \\
\text { ferences } \\
\text { in ef- } \\
\text { fect that } \\
\text { could af- } \\
\text { fect } \\
\text { health }\end{array}$ & $\begin{array}{l}\text { No SRs } \\
(0 / \\
14) \text { con- } \\
\text { ducted } \\
\text { sub- } \\
\text { group } \\
\text { analyses }\end{array}$ & $\begin{array}{l}\text { No SRs } \\
(0 / \\
64) \text { con- } \\
\text { ducted } \\
\text { sub- } \\
\text { group }\end{array}$ & $\begin{array}{l}\text { Can't } \\
\text { tell- 3/ } \\
19 \quad \text { SRs } \\
\text { assessed } \\
\text { ef- } \\
\text { fects on }\end{array}$ & $\begin{array}{l}\text { Can't } \\
\text { tell- } 8 / \\
30 \quad \text { SRs } \\
\text { assessed } \\
\text { ef- } \\
\text { fects on }\end{array}$ & $\begin{array}{l}\text { not de- } \\
\text { scribed }\end{array}$ & $\begin{array}{l}\text { Not de- } \\
\text { scribed }\end{array}$ \\
\hline
\end{tabular}

How effects on health equity are assessed in systematic reviews of interventions (Review) 
Table 3. Subgroup analyses: assessment against credibility criteria

(Continued)

\begin{tabular}{|c|c|c|c|c|c|c|c|c|c|c|c|}
\hline & & & & & $\begin{array}{l}\text { equity in } \\
4 / 20 \\
\text { SRs }\end{array}$ & & $\begin{array}{l}\text { analy- } \\
\text { sis across } \\
\text { race }\end{array}$ & $\begin{array}{l}\text { health } \\
\text { inequal- } \\
\text { ities }\end{array}$ & $\begin{array}{l}\text { health } \\
\text { inequal- } \\
\text { ities }\end{array}$ & & \\
\hline $\begin{array}{l}\text { Statisti- } \\
\text { cally sig- } \\
\text { nifi- } \\
\text { cant dif- } \\
\text { ference }\end{array}$ & $\begin{array}{l}\text { Not de- } \\
\text { scribed, } \\
\text { state } \\
\text { "poten- } \\
\text { tial dif- } \\
\text { fer- } \\
\text { ence" in } \\
3 \text { out of } \\
31 \text { sys- } \\
\text { tematic } \\
\text { reviews }\end{array}$ & $\begin{array}{l}\text { Yes, in } 1 / \\
95 S R s\end{array}$ & $\begin{array}{l}\text { Not de- } \\
\text { scribed }\end{array}$ & $\begin{array}{l}\text { Yes, 5/ } \\
16 \quad \text { SRs } \\
\text { reported } \\
\text { statisti- } \\
\text { cally sig- } \\
\text { nifi- } \\
\text { cant dif- } \\
\text { ference } \\
\text { in effects } \\
\text { across } \\
\text { gender } \\
\text { or race }\end{array}$ & $\begin{array}{l}\text { Not de- } \\
\text { scribed }\end{array}$ & No data & No data & $\begin{array}{l}\text { Not de- } \\
\text { scribed }\end{array}$ & $\begin{array}{l}\text { Not de- } \\
\text { scribed }\end{array}$ & $\begin{array}{l}\text { Not de- } \\
\text { scribed }\end{array}$ & $\begin{array}{l}\text { Not de- } \\
\text { scribed }\end{array}$ \\
\hline $\begin{array}{l}\text { A priori } \\
\text { hypoth- } \\
\text { esis }\end{array}$ & $\begin{array}{l}\text { Not de- } \\
\text { scribed }\end{array}$ & Yes & Yes & $\begin{array}{l}\text { Not de- } \\
\text { scribed }\end{array}$ & $\begin{array}{l}\text { Not de- } \\
\text { scribed }\end{array}$ & No data & No data & yes & yes & $\begin{array}{l}\text { Not de- } \\
\text { scribed }\end{array}$ & $\begin{array}{l}\text { Not de- } \\
\text { scribed }\end{array}$ \\
\hline $\begin{array}{l}\text { One of a } \\
\text { small } \\
\text { number } \\
\text { of hy- } \\
\text { potheses } \\
\text { tested }\end{array}$ & $\begin{array}{l}\text { Not de- } \\
\text { scribed }\end{array}$ & Yes & $\begin{array}{l}\text { Not de- } \\
\text { scribed }\end{array}$ & $\begin{array}{l}\text { Not de- } \\
\text { scribed }\end{array}$ & $\begin{array}{l}\text { Not de- } \\
\text { scribed }\end{array}$ & No data & No data & $\begin{array}{l}\text { Not de- } \\
\text { scribed }\end{array}$ & $\begin{array}{l}\text { Not de- } \\
\text { scribed }\end{array}$ & $\mathrm{y}$ & $\begin{array}{l}\text { Not de- } \\
\text { scribed }\end{array}$ \\
\hline $\begin{array}{l}\text { Differ- } \\
\text { ences } \\
\text { sug- } \\
\text { gested } \\
\text { by } \\
\text { within } \\
\text { study } \\
\text { compar- } \\
\text { isons }\end{array}$ & $\begin{array}{l}\text { Not de- } \\
\text { scribed }\end{array}$ & Yes & $\begin{array}{l}\text { Not de- } \\
\text { scribed }\end{array}$ & $\begin{array}{l}\text { Not de- } \\
\text { scribed }\end{array}$ & $\begin{array}{l}\text { Not de- } \\
\text { scribed }\end{array}$ & No data & No data & $\begin{array}{l}\text { Not de- } \\
\text { scribed }\end{array}$ & $\begin{array}{l}\text { Not de- } \\
\text { scribed }\end{array}$ & $\begin{array}{l}\text { Not de- } \\
\text { scribed }\end{array}$ & $\begin{array}{l}\text { Not de- } \\
\text { scribed }\end{array}$ \\
\hline $\begin{array}{l}\text { Differ- } \\
\text { ence } \\
\text { consis- } \\
\text { tent } \\
\text { across } \\
\text { studies }\end{array}$ & $\begin{array}{l}\text { Not de- } \\
\text { scribed }\end{array}$ & $\begin{array}{l}\text { NA- } \\
\text { only } 1 \\
\text { study }\end{array}$ & $\begin{array}{l}\text { Not de- } \\
\text { scribed }\end{array}$ & $\begin{array}{l}\text { Not de- } \\
\text { scribed }\end{array}$ & $\begin{array}{l}\text { Not de- } \\
\text { scribed }\end{array}$ & No data & No data & $\begin{array}{l}\text { Not de- } \\
\text { scribed }\end{array}$ & $\begin{array}{l}\text { Not de- } \\
\text { scribed }\end{array}$ & $\begin{array}{l}\text { Not de- } \\
\text { scribed }\end{array}$ & $\begin{array}{l}\text { Not de- } \\
\text { scribed }\end{array}$ \\
\hline $\begin{array}{l}\text { Indi- } \\
\text { rect evi- } \\
\text { dence to } \\
\text { sup- } \\
\text { port hy- }\end{array}$ & $\begin{array}{l}\text { Yes, } \\
\text { evidence } \\
\text { that } \\
\text { cardio- } \\
\text { vascular }\end{array}$ & $\begin{array}{l}\text { yes- eco- } \\
\text { nomic } \\
\text { ratio- } \\
\text { nale why } \\
\text { trans- }\end{array}$ & $\begin{array}{l}\text { Yes, } \\
\text { smoking } \\
\text { is associ- } \\
\text { ated } \\
\text { with so- }\end{array}$ & $\begin{array}{l}\text { Not de- } \\
\text { scribed }\end{array}$ & $\begin{array}{l}\text { Not de- } \\
\text { scribed }\end{array}$ & No data & No data & Yes & Yes & Yes & Yes \\
\hline
\end{tabular}

How effects on health equity are assessed in systematic reviews of interventions (Review)

Copyright @ 2010 The Cochrane Collaboration. Published by John Wiley \& Sons, Ltd. 
Table 3. Subgroup analyses: assessment against credibility criteria (Continued)

\begin{tabular}{|c|c|c|c|c|c|c|c|c|c|c|c|}
\hline pothesis & $\begin{array}{l}\text { risk } \\
\text { factors, } \\
\text { presen- } \\
\text { tation, } \\
\text { treat- } \\
\text { ment } \\
\text { and } \\
\text { treat- } \\
\text { ment } \\
\text { out- } \\
\text { comes } \\
\text { vary } \\
\text { between } \\
\text { men and } \\
\text { women }\end{array}$ & $\begin{array}{l}\text { port in- } \\
\text { centives } \\
\text { would } \\
\text { work } \\
\text { better } \\
\text { for } \\
\text { poorer } \\
\text { people }\end{array}$ & $\begin{array}{l}\text { cial dis- } \\
\text { advan- } \\
\text { tage }\end{array}$ & & & & & & & & \\
\hline $\begin{array}{l}\text { Statis- } \\
\text { tical sub- } \\
\text { group by } \\
\text { treat- } \\
\text { ment in- } \\
\text { terac- } \\
\text { tion }\end{array}$ & $\begin{array}{l}\text { Not de- } \\
\text { scribed }\end{array}$ & $\begin{array}{l}\text { Not de- } \\
\text { scribed }\end{array}$ & $\begin{array}{l}\text { Not de- } \\
\text { scribed }\end{array}$ & $\begin{array}{l}\text { Not de- } \\
\text { scribed }\end{array}$ & $\begin{array}{l}\text { Not de- } \\
\text { scribed }\end{array}$ & No data & No data & $\begin{array}{l}\text { Not de- } \\
\text { scribed }\end{array}$ & $\begin{array}{l}\text { Not de- } \\
\text { scribed }\end{array}$ & $\begin{array}{l}\text { Not de- } \\
\text { scribed }\end{array}$ & $\begin{array}{l}\text { Not de- } \\
\text { scribed }\end{array}$ \\
\hline $\begin{array}{l}\text { Primary } \\
\text { stud- } \\
\text { ies strati- } \\
\text { fied ran- } \\
\text { domiza- } \\
\text { tion } \\
\text { by sub- } \\
\text { group of } \\
\text { interest }\end{array}$ & $\begin{array}{l}\text { Not de- } \\
\text { scribed }\end{array}$ & $\begin{array}{l}\text { Not de- } \\
\text { scribed }\end{array}$ & $\begin{array}{l}\text { Not de- } \\
\text { scribed }\end{array}$ & $\begin{array}{l}\text { Not de- } \\
\text { scribed }\end{array}$ & $\begin{array}{l}\text { Not de- } \\
\text { scribed }\end{array}$ & No data & No data & $\begin{array}{l}\text { Not de- } \\
\text { scribed }\end{array}$ & $\begin{array}{l}\text { Not de- } \\
\text { scribed }\end{array}$ & $\begin{array}{l}\text { Not de- } \\
\text { scribed }\end{array}$ & $\begin{array}{l}\text { Not de- } \\
\text { scribed }\end{array}$ \\
\hline
\end{tabular}




\section{A P P E N D I C E S}

\section{Appendix I. MEDLINE search strategy}

The search terms for MEDLINE are listed below, along with the number of hits obtained from searching MEDLINE from January 1960 to January week 2, 2009. The search strategy will be adapted for the other electronic databases.

1 exp Meta-Analysis as Topic/ 8694

2 systematic review.tw. 13239

3 meta-analys\$.tw. 21728

4 meta-epidemiolog\$.tw. 10

5 exp "Review Literature as Topic"/ 3979

6 (Cochrane adj2 review).tw. 967

7 OR/1-6 39977

8 (gender-based OR gender-related OR gender differences OR gender factors).mp. 12856

9 ((sex OR gender) adj2 (analysis OR specific OR difference? OR factor? OR inequit\$ OR disparit\$ OR inequalit\$)).mp. 196205

10 exp sex factors/ 164145

11 exp geriatrics/ 23034

12 ((ethnic\$ OR race OR racial OR religio\$ OR cultur\$ OR minorit\$ OR refugee OR indigenous OR aboriginal) adj3 (analysis OR difference\$ OR specific OR disparit\$ OR inequalit\$ OR inequit\$)).tw. 26985

13 exp homosexuality/ 16581

14 exp disabled persons/ 35507

15 ((poverty OR low-income OR socioeconomic\$ OR social) adj2 (analysis OR disadvantage\$ OR specific OR difference? OR factor? OR inequalit\$ OR depriv\$ OR inequit\$ OR disparit\$)).mp. 87592

16 exp Educational Status/ 26647

17 exp Socioeconomic Factors/ 248934

18 ((discriminat\$ OR social exclu\$ OR social inclu\$) adj3 (religion OR culture OR race OR racial OR aboriginal OR indigenous OR ethnic\$)).tw. 475

19 ((urban OR rural OR inner-city OR slum) adj2 (difference\$ OR specific OR analysis OR inequit\$ OR disparit\$ OR inequalit\$)).tw. 1464

20 ((resource-poor OR (low-income adj countr\$) OR (middle income adj countr\$) OR africa OR developing countr\$ OR south america OR china OR asia OR latin america) adj2 (relevance OR analysis OR specific OR difference OR applicab\$ OR inequit\$ OR disparit\$ OR inequalit\$)).tw. 541

$21 \mathrm{OR} / 8-20522320$

227 AND 211672

\section{Appendix 2. Search strategies in other databases}

\section{CINAHL 1998 to Jan $282009=608$ results:}

TX ( meta-analysis OR systematic review OR meta-epidemiolog*) and ( TX sex OR gender OR race OR ethnic OR indigenous OR socioeconomic OR elderly OR homosexual OR urban OR rural OR aboriginal OR slum OR developing country OR refugee OR poverty OR education ) and ( subgroup analysis OR sensitivity analysis OR specific OR equity OR disparity OR inequality )

Index to foreign legal periodicals

How effects on health equity are assessed in systematic reviews of interventions (Review) 


\begin{tabular}{|c|c|c|c|c|}
\hline 1 & $\begin{array}{l}\text { ((meta-analysis or system- } \\
\text { atic review or meta-epidemi- } \\
\text { olog\$) and (sex or gender or } \\
\text { race or ethnic or indigenous } \\
\text { or socioeconomic or elderly } \\
\text { or homosexual or urban or ru- } \\
\text { ral or aboriginal or slum or } \\
\text { developing country or refugee } \\
\text { or poverty or education) and } \\
\text { (subgroup analysis or sensitiv- } \\
\text { ity analysis or specific or eq- } \\
\text { uity or disparity or inequality) } \\
\text { ).mp }\end{array}$ & 0 & Advanced & - \\
\hline 2 & meta-analysis.tw. & 0 & Advanced & - \\
\hline 3 & systematic review.tw. & 8 & Advanced & DISPLAY \\
\hline 4 & meta-synthesis.tw. & 0 & Advanced & - \\
\hline 5 & meta-analysis.mp. & 0 & Advanced & - \\
\hline 6 & synthesis.mp. & 17 & Advanced & DISPLAY \\
\hline 7 & or/1-6 & 25 & Advanced & DISPLAY \\
\hline
\end{tabular}

\section{ERIC- Jan 28, 2009- 90 records}

((meta-analysis or ("systematic review") or meta-epidemiol\$) or DE=meta-analysis) and(((gender-based or sex-based) and KW=((gender or sex) and (based or specific or difference))) or((educational AND (status OR attainment)) WITHIN 2 (specific or difference* OR disparit* OR inequalit* OR (subgroup analysis) OR inequit*)) or((poverty OR low-income OR socioeconomic* OR social) WITHIN 2 (specific or difference* OR disparit* OR inequalit* OR (subgroup analysis) OR inequit*)) or((geriatric OR elderly) WITHIN 2 ((subgroup analysis) OR difference* OR disparit* OR inequit* OR inequalit* OR specific)) or(“developing nations” WITHIN 2 (difference* OR specific OR (subgroup analysis) OR inequit* OR inequalit*)) or((urban OR rural OR inner-city OR slum) WITHIN 2 (specific or difference* OR disparit* OR inequalit* OR (subgroup analysis) OR inequit*)) or((ethnic* OR minorit* OR racial OR cultur* OR aboriginal OR religio* OR indigenous OR refugee) WITHIN 2 (specific or difference* OR disparit* OR inequalit* OR (subgroup analysis) OR inequit*)) or(disabilit* WITHIN 2 (specific OR difference OR inequit* OR inequal* OR "subgroup analysis" OR discriminat $\left.\left.{ }^{*}\right)\right)$ )

Education abstracts- Jan 28, 2009, 176 records

Search Query \#20 ((meta-analys* or (systematic review) or meta-epidemiol*) or meta-synthes*) and $\left(\left(\right.\right.$ religio* $^{*}$ or cultur $\left.^{*}\right)$ or ((education status) or (education attainment) or literacy) or ((socioeconomic status) or poverty or low-income) or ((developing countries) or africa or (China OR South America OR Asia OR Eastern Europe)) or (homosexual or lesbian) or(elderly or geriatr*) or (gender or sex) or ((urban or rural or (inner-city OR slum)) or (race or ethnic* or (aboriginal OR indigenous OR refugee)) or (occupation or blue-collar))) (Copy Query)

PAIS 1983 to jan 28, 2009, 18 records

$((($ meta-analys* or (systematic review) or meta-epidemiol*) or meta-synthes*) and ((religio* or cultur*) or ((education status) or (education attainment) or literacy) or ((socioeconomic status) or poverty or low-income) or ((developing countries) or africa or (China OR South America OR Asia OR Eastern Europe)) or (homosexual or lesbian) or(elderly or geriatr*) or (gender or sex) or ((urban

How effects on health equity are assessed in systematic reviews of interventions (Review) 
or rural or (inner-city OR slum)) or (race or ethnic* or (aboriginal OR indigenous OR refugee)) or (occupation or blue-collar)))) and((specific or subgroup or sensitivity) or ((equit* OR inequit*) or disparit* or inequalit*) or (factor or difference))

social services abstracts, $\mathbf{5 4 5}$ records

$\left(\left(\left(\right.\right.\right.$ meta-analys $s^{*}$ or (systematic review) or meta-epidemiol*) or meta-synthes*) and ((religio* or cultur*) or ((education status) or (education attainment) or literacy) or ((socioeconomic status) or poverty or low-income) or ((developing countries) or africa or (China OR South America OR Asia OR Eastern Europe)) or (homosexual or lesbian) or(elderly or geriatr*) or (gender or sex) or ((urban or rural or (inner-city OR slum)) or (race or ethnic* or (aboriginal OR indigenous OR refugee)) or (occupation or blue-collar)))) and((specific or subgroup or sensitivity) or ((equit* OR inequit*) or disparit* or inequalit*) or (factor or difference))

\section{Sociological abstracts- 1005}

(((meta-analys* or (systematic review) or meta-epidemiol* or meta-synthes*) and (religio* or cultur* or (education status) or (education attainment) or literacy or (socioeconomic status) or poverty or low-income) or (developing countries) or africa or (China OR South America OR Asia OR Eastern Europe) or (homosexual or lesbian) or(elderly or geriatr*) or (gender or sex) or (urban or rural or (inner-city OR slum)) or (race or ethnic* or (aboriginal OR indigenous OR refugee)) or (occupation or blue-collar)))) and( (specific or subgroup or sensitivity) or (equit* OR inequit*) or disparit* or inequalit*) or (factor or difference))

\section{Cochrane Methodology Register: 149 records}

(((meta-analys* or (systematic review) or meta-epidemiol*) or meta-synthes*) and ((religio* or cultur*) or ((education status) or (education attainment) or literacy) or ((socioeconomic status) or poverty or low-income) or ((developing countries) or africa or (China OR South America OR Asia OR Eastern Europe)) or (homosexual or lesbian) or(elderly or geriatr*) or (gender or sex) or ((urban or rural or (inner-city OR slum)) or (race or ethnic* or (aboriginal OR indigenous OR refugee)) or (occupation or blue-collar)))) and((specific or subgroup or sensitivity) or ((equit* OR inequit*) or disparit* or inequalit*) or (factor or difference))

\section{Cochrane HTA database, 156 records}

(((meta-analys* or (systematic review) or meta-epidemiol*) or meta-synthes*) and ((religio* or cultur*) or ((education status) or (education attainment) or literacy) or ((socioeconomic status) or poverty or low-income) or ((developing countries) or africa or (China OR South America OR Asia OR Eastern Europe)) or (homosexual or lesbian) or(elderly or geriatr*) or (gender or sex) or ((urban or rural or (inner-city OR slum)) or (race or ethnic* or (aboriginal OR indigenous OR refugee)) or (occupation or blue-collar)))) and((specific or subgroup or sensitivity) or ((equit* OR inequit*) or disparit* or inequalit*) or (factor or difference))

\section{Digital dissertations, 98 records}

(((meta-analys* or (systematic review) or meta-epidemiol*) or meta-synthes*) and ((religio* or cultur*) or ((education status) or (education attainment) or literacy) or ((socioeconomic status) or poverty or low-income) or ((developing countries) or africa or (China OR South America OR Asia OR Eastern Europe)) or (homosexual or lesbian) or(elderly or geriatr*) or (gender or sex) or ((urban or rural or (inner-city OR slum)) or (race or ethnic* or (aboriginal OR indigenous OR refugee)) or (occupation or blue-collar)))) and((specific or subgroup or sensitivity) or ((equit* OR inequit*) or disparit* or inequalit*) or (factor or difference))

\section{Appendix 3. Data extraction form items}

\section{Ref ID}

Author

Year

PROGRESS dimension

Definition equity (by author)

How is judgment of equity made? Ie fairness and avoidability?

How effects on health equity are assessed in systematic reviews of interventions (Review)

Copyright @ 2010 The Cochrane Collaboration. Published by John Wiley \& Sons, Ltd. 


\section{(Continued)}

Proxy measures used for PROGRESS-Plus? (e.g. nutritional status)

Reason/rationale for assessing equity

Number meta-analyses

Quality: Selection bias: how was sample of systematic reviews selected? Is there likelihood of selection bias?

Quality: Attrition bias: potential for bias in the exclusion of systematic reviews from analysis. Were any systematic reviews excluded and why

Quality: Detection bias: potential for bias in the assessment of analytic methods and outcomes in cohorts of systematic reviews. How did studies extract details of analysis of effects on health equity

outcomes (benefits, harms, costs)

Quant measure of gaps/gradients

Statistical methods used (e.g. meta-regression, subgroup analysis)

Methods of comparing gap (relative, absolute, gradient, risk difference)

Describe whether PROGRESS + is mentioned in SR- in introduction, methods, discussion

Describe whether SRs describe population across PROGRESS+

Describe whether SRs include studies of targeted interventions aimed at disadvantaged

Describe outcomes related to equity of coverage or access

Describe whether primary studies included in the SRs stratify analyses by PROGRESS

Describe whether subgroup analyses were planned or conducted across PROGRESS in the SRs

Subgroup analysis described in sufficient detail to answer 7 questions

Analytic- assess association of PROGRESS + factor with effect size

Analytic: compare effect size between two groups using odds ratio, risk difference, relative risk

Analytic- assess likely impact on disadvantaged populations using checklists for applicability

Effect size

Standard error

$95 \%$ CI

How effects on health equity are assessed in systematic reviews of interventions (Review)

Copyright $\odot 2010$ The Cochrane Collaboration. Published by John Wiley \& Sons, Ltd. 
(Continued)

Expertise required to assess equity effects (as described by author, or paste in methods)

Availability of data to assess equity gap (as described by author)

Useability for end-user? (judgment by extractor or paste author's description

Advantages of method chosen to assess gap, as described by author?

Disdavantages of method chosen to assess gap, as described by author?

Clinically important difference?

Statistically significant difference?

A priori hypothesis

Subgroup analysis is one of small number of hypotheses tested?

differences suggested by within study comparisons

Difference consistent across studies?

Indirect evidence to support hypothesis?

Implications for policy, practice, research based on equity, equality analysis?

How was this study found? (searching databases, handsearching etc

Factors associated with equity differences (e.g. study design, implementation adherence, compliance)

Limitations as described by author

Strengths as described by author

\section{Appendix 4. SUPPORT Collaboration checklists for applicability, equity and scaling up}

Available from: http://www.support-collaboration.org/summaries/methods.htm

\section{APPLICABILITY}

Consider differences in:

structural elements of health systems (such that an intervention could not work in the same way)

on-the-ground realities and constraints (that might substantially alter the potential benefits of the intervention)

baseline conditions (different absolute effects, even if the relative effectiveness was the same)

perspectives and influences of health system stakeholders (such that the intervention may not be accepted or taken up in the

EQUITY

How effects on health equity are assessed in systematic reviews of interventions (Review)

Copyright $\odot 2010$ The Cochrane Collaboration. Published by John Wiley \& Sons, Ltd. 
- Are there plausible reasons for anticipating differences in the relative effectiveness of the intervention in disadvantaged settings within the country?

- Are there likely to be different baseline conditions within the country, so that the problem would be more or less important in disadvantaged settings within the country?

Are there likely to be different baseline conditions in disadvantaged settings within the country, so that the absolute effectiveness would be different?

Are there important considerations that should be given to implementing the intervention to ensure that inequities are not increased and that they are reduced

\section{SCALING UP}

What are the most important economic consequences?

What information is there about the total resource implications of expanding coverage and sustaining an intervention?

Is there important uncertainty about medium to long-term economic consequences?

Is there important uncertainty about the applicability of any reported economic consequences?

\section{Appendix 5. Scottish Intercollegiate Guidelines Network [SIGN] grades of assessment}

\section{Grade Assessment of individual studies}

$1++$ High quality meta analysis, systematic review of randomized controlled trials (RCT), or RCT with very low risk of bias

1+ Well-conducted meta analysis, systematic review of RCTs, or RCT with a low risk of bias

1- Meta analysis, systematic review of RCTs, or RCT with a high risk of bias

$2++$ High quality systematic reviews of case-control or cohort studies, High quality case-control or cohort studies with a very low risk of confounding, bias, or chance and a high probability that the relationship is causal

$2+$ Well conducted case control or cohort studies with a low risk of confounding, bias, or chance and a moderate probability that the relationship is causal

2- Case control or cohort studies with a high risk of confounding, bias, or chance and a significant risk that the relationship is not causal

3 Non-analytic studies, e.g. case reports, case series

4 Expert opinion

Assessment of all evidence for each intervention

A: At least 1 meta analysis, systematic review, or RCT rated as 1++, directly applicable to the target population; or a systematic review of RCTs or a body of evidence consisting primarily of studies rated as 1+, directly applicable to the target population and demonstrating consistent overall results

B: Body of evidence including studies rated as $2++$, directly applicable to the target population, and demonstrating consistent overall results; or extrapolated evidence from studies rated as $1++$ or $1+$

C: Body of evidence including studies rated as 2+, directly applicable to the target population and demonstrating consistent overall results; or extrapolated evidence from studies rated as $2++$

D: Body of evidence 3 or 4; or extrapolated evidence from studies rated as $2+\mathrm{D}$

\section{Appendix 6. SIGN Considered Judgment Form}

Considered judgement on quality of evidence
Key question:
Evidence table ref:

How effects on health equity are assessed in systematic reviews of interventions (Review) 


\section{Volume of evidence}

Comment here on any issues concerning the quantity of evidence available on this topic and its methodological quality.

\section{Applicability}

Comment here on the extent to which the evidence is directly applicable to the NHS in Scotland.

\section{Generalisability}

Comment here on how reasonable it is to generalise from the results of the studies used as evidence to the target population for this guideline.

\section{Consistency}

Comment here on the degree of consistency demonstrated by the available of evidence. Where there are conflicting results, indicate how the group formed a judgement as to the overall direction of the evidence

\section{Clinical impact}

Comment here on the potential clinical impact that the intervention in question might have - e.g. size of patient population; magnitude of effect; relative benefit over other management options; resource implications; balance of risk and benefit.

\section{Other factors}

Indicate here any other factors that you took into account when assessing the evidence base.

\section{Appendix 7. Biological plausibility and feasibility in LMIC grades of evidence}

I. Evidence of no benefit. Interventions for which evidence exists showing they have no important benefits-either singly or in combination with other measures-for perinatal or neonatal health.

II. No evidence of benefit. Interventions for which evidence for or against an effect was absent.

III. Uncertain evidence of benefit. Interventions for which there was some evidence of benefit, but contradictory evidence, or issues such as study design, location, or size precluded any firm conclusions. These interventions merit further assessment in low-income and middle-income countries.

IV. Evidence of efficacy. Interventions effective in reducing perinatal or neonatal mortality, or primary determinants thereof, but there is a lack of data on effectiveness in large-scale programme conditions.

V. Evidence of efficacy and effectiveness. Interventions of incontrovertible efficacy and which seem feasible for large-scale implementation based on effectiveness trials.

How effects on health equity are assessed in systematic reviews of interventions (Review) 


\section{CONTRIBUTIONSOFAUTHORS}

VW developed the idea for the review, wrote the protocol, and developed the search strategy. JM reviewed the search strategy. VW,JdM, $\mathrm{MB}, \mathrm{BD}$ and EU screened articles for inclusion and extracted data. MB and JPP reviewed Spanish articles for inclusion. All authors contributed to analysis, writing, and reviewed the final draft.

\section{DECLARATIONSOF INTEREST}

BK, EU, MP, PT, and VW are members of the Cochrane and Campbell Equity Methods Group. MP and PT are Co-Conveners of the Cochrane and Campbell Equity Methods Group; EU is the Field Administrator.

Some of the authors of this review team are authors on one or more of the empirical studies included in this review (PT, MP, EK, EU, VW, JM, GW). We sought to minimize the possible bias of analysis and synthesis of these studies by having studies co-authored by authors of this review team extracted by a review author who was not a co-author (JdM or MB).

\section{SOURCES OF SUPPORT}

\section{Internal sources}

- No sources of support supplied

\section{External sources}

- Canadian Institutes of Health Research doctoral fellowship, Canada.

Funding for doctoral degree from government of Canada

- Department of Health (England), UK.

Cochrane systematic review incentive program

\section{DIFFERENCES BETWEEN PROTOCOLANDREVIEW}

We clarified our inclusion criteria by stating that we are explicitly not including studies with surrogate outcomes for health (e.g. vaccination rates and high risk behaviours), as follows: We excluded studies which measured inequalities in surrogate outcomes for health across PROGRESS-Plus factors such as vaccination rates (Shea 2009) or high-risk behaviours (Vergidis 2009a).

\section{NDEX TERMS}

\section{Medical Subject Headings (MeSH)}

*Health Status Disparities; * Review Literature as Topic; Age Factors; Continental Population Groups; Developing Countries; Ethnology; Research Design [standards]; Sex Factors; Socioeconomic Factors 


\section{MeSH check words}

Humans

How effects on health equity are assessed in systematic reviews of interventions (Review) 